\title{
Using stages of change to examine fear, threat, efficacy, and safety climate perceptions in health care workers who routinely handle needles and sharps
}

\author{
Brian Thomas Day \\ West Virginia University
}

Follow this and additional works at: https://researchrepository.wvu.edu/etd

\section{Recommended Citation}

Day, Brian Thomas, "Using stages of change to examine fear, threat, efficacy, and safety climate perceptions in health care workers who routinely handle needles and sharps" (1999). Graduate Theses, Dissertations, and Problem Reports. 3127.

https://researchrepository.wvu.edu/etd/3127

This Dissertation is protected by copyright and/or related rights. It has been brought to you by the The Research Repository @ WVU with permission from the rights-holder(s). You are free to use this Dissertation in any way that is permitted by the copyright and related rights legislation that applies to your use. For other uses you must obtain permission from the rights-holder(s) directly, unless additional rights are indicated by a Creative Commons license in the record and/ or on the work itself. This Dissertation has been accepted for inclusion in WVU Graduate Theses, Dissertations, and Problem Reports collection by an authorized administrator of The Research Repository @ WVU.

For more information, please contact researchrepository@mail.wvu.edu. 
USING STAGES OF CHANGE TO EXAMINE FEAR, THREAT, EFFICACY, AND SAFETY CLIMATE PERCEPTIONS IN HEALTH CARE WORKERS WHO ROUTINELY HANDLE NEEDLES AND SHARPS

\author{
By \\ Brian T. Day \\ A DISSERTATION \\ Submitted to \\ The College of Human Resources and Education \\ at \\ West Virginia University \\ in partial fulfillment of the requirements \\ for the degree of \\ Doctor of Education \\ in \\ Educational Psychology \\ Department of Advanced Educational Studies \\ Anne H. Nardi, Ph.D., Chair \\ Floyd L. Stead, Ed.D. \\ Ronald C. Althouse, Ph.D. \\ Daniel E. Hursh, Ph.D. \\ Steve Booth-Butterfield, Ed.D.
}

Morgantown, West Virginia

1999

Copyright 1999 Brian T. Day 


\title{
ABSTRACT \\ USING STAGES OF CHANGE TO EXAMINE FEAR, THREAT, EFFICACY, AND SAFETY CLIMATE PERCEPTIONS IN HEALTH CARE WORKERS WHO ROUTINELY HANDLE NEEDLES AND SHARPS
}

\author{
By Brian T. Day
}

Standard precautions are mandated for the purpose of decreasing the risk of bloodborne pathogen transmission of diseases, namely human immunodeficiency virus (HIV) and hepatitis B infections. One of the stipulations of standard precautions is that used needles should not be recapped and should be disposed of in an appropriate sharps container. The rate of needle stick injuries among health care workers remains at a high level despite the 1992 passage of the Occupational Safety and Health Administration (OSHA) regulations regarding standard precautions. The role fear plays in decisions regarding individual health related behaviors such as intravenous drug use has been critically examined, but fear related to occupationally related behavior (e.g., needle re-capping and disposal by health care workers) has received little attention. With the severe threat of bloodborne diseases such as AIDS and Hepatitis B, it is important to determine what role fear plays in enhancing or deterring compliance with standard precautions (specifically, not recapping used needles). The purpose of this study was to determine the differences in fear, threat, efficacy, and safety climate perceptions across Prochaska's five stages of change (transtheoretical model) for health care workers who routinely handle needles and/or other sharps. The study used a self-administered mail questionnaire to assess health care worker perceptions. Results indicated that a clear risk of contracting HIV and Hepatitis B exists among health care workers in the sample. $72 \%$ of the sample had experienced a needle stick and $56 \%$ of those had been stuck more than one time. More alarming was the finding that $38 \%$ of the reported needle sticks involved blood contaminated needles.

Surprisingly, neither fear nor threat levels differed across the stages of change. Efficacy levels were found to significantly increase across the stages as Prochaska and colleagues would predict. All four of the safety climate factors were found to significantly differ across the stages of change, indicating that the environmental context (occupational setting) is important in moving effectively through the behavior change process. 


\section{Acknowledgments}

Wow, where do I start. This dissertation is a culmination of work that started more than 6 years ago. So much has happened in those six years that could have stalled the ambition I had to finish the work to complete the doctorate degree. There were the many extended hospital stays with my son and working on doctoral course material at Ronald McDonald Houses in various parts of the country, there were the two semesters I enrolled full-time to meet residency requirements while working full-time, and finally, the numerous setbacks related to getting my research competency product completed. Through all the tragedy and turmoil I have become a better person, researcher, father, husband, and finally a doctor of education!

There are so many people to thank and recognize, for it is all their contributions, encouragement, and love that have made this achievement possible. Thank you Sedigheh for your invaluable assistance during the final 3 years of my studies, you helped make this dream come true. Thank you Stephanie and Malina for your clerical assistance, and Lisa, Judy, Jarrod, Nikki, Chelsey, and Lindae for your help in stuffing, sorting, and labeling envelopes, and Dorothy for your help in completing all the data entry and invaluable insights into the project. Special thanks to Dr. Ray Sinclair who is a mentor, colleague, and friend for his humor during the entire process! I want to thank all my committee members for their willingness to stick with me so long, especially Dr. Ron Althouse who has seen me through 20 years and three degrees at West Virginia University! Very special thanks also go to the late Dr. John Paterson who provided invaluable insights into methodological and statistical issues throughout my doctoral studies. My only regret about obtaining the Ed.D degree is that he cannot be here with me to share in this long coming achievement. But, I know he is watching and is smiling. Thanks John. Also, thanks to Ann 
Crabtree who put up with all my last minute requests throughout my doctoral work. Lastly, I want to thank my partner in life, my wife, and dear friend Lindae. There were times I wondered if I would ever get finished and she always stuck with me and was my pillar of support.

This work I dedicate to my daughter, Chelsey, so that she can someday look back on what it took to complete this degree and realize that she can do anything she puts her mind to doing. I also dedicate this work to my son Mitchell, who despite his severe disability, makes me smile each and every day and is a constant reminder that we can take nothing in life for granted. Finally, I thank God for giving me the wisdom, strength, and perseverence to arrive at this truly satisfying juncture on the road called life. 


\section{TABLE OF CONTENTS}

TITLE PAGE i

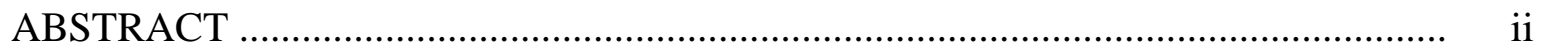

ACKNOWLEDGMENTS .......................................................................

TABLE OF CONTENTS ........................................................................... $\quad \mathrm{v}$

LIST OF TABLES ................................................................................. viii

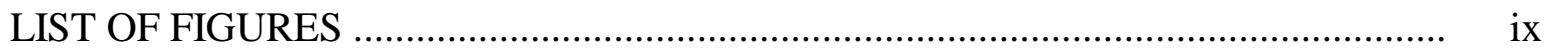

CHAPTER ONE .......................................................................................

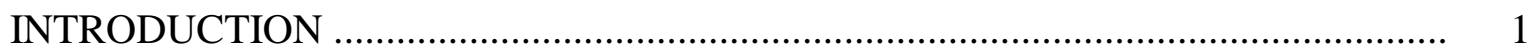

Significance of the Study ...................................................................... 4

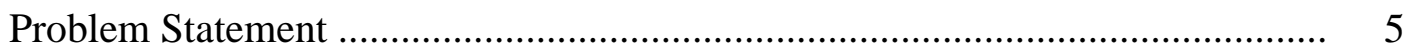

Research Questions ......................................................................... 5

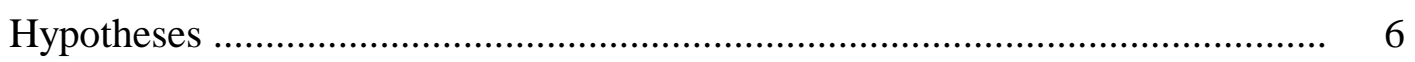

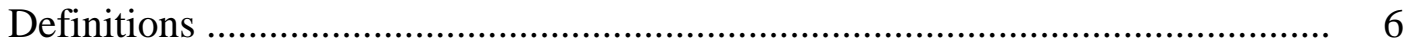

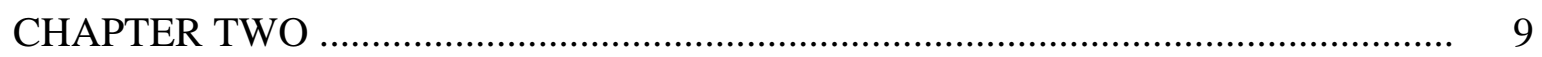

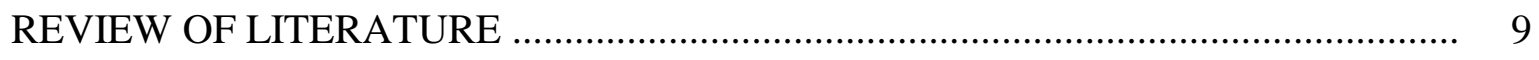

Standard Precautions Training Programs ................................................. 9

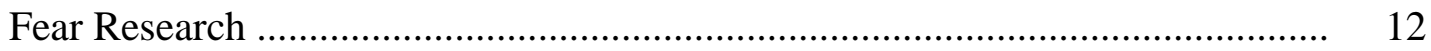

The Extended Parallel Process Model .............................................................. 19

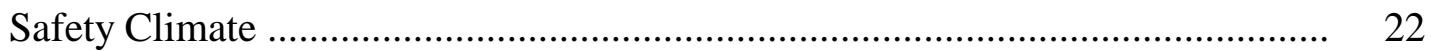




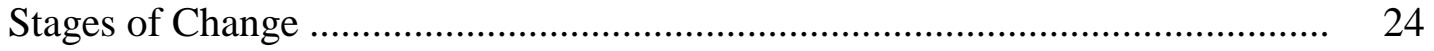

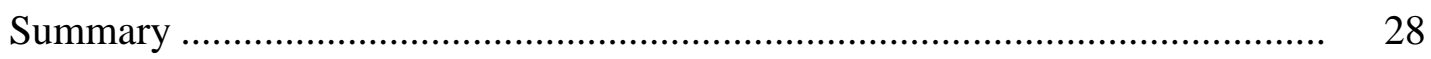

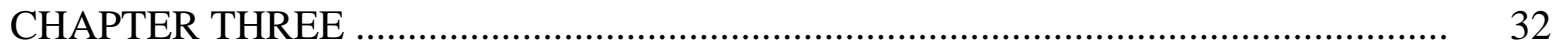

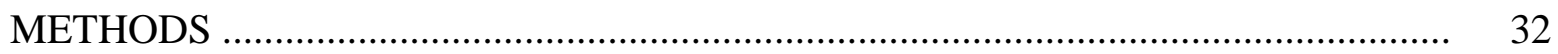

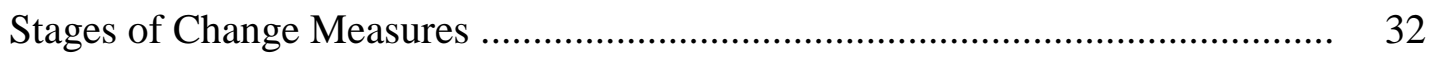

Fear, Threat, and Efficacy Measures .................................................................. 33

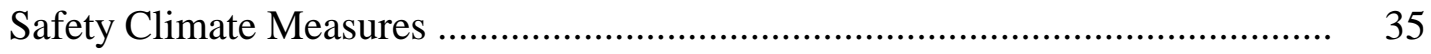

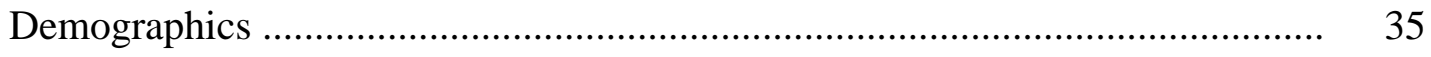

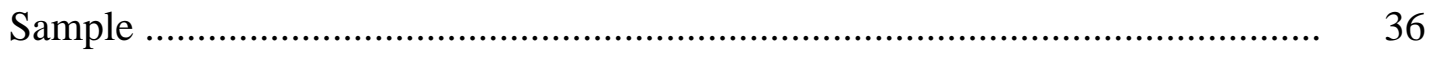

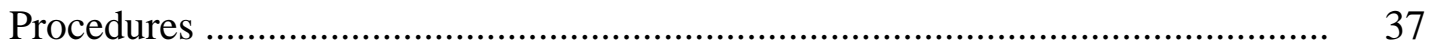

Data Analysis ..................................................................................... 38

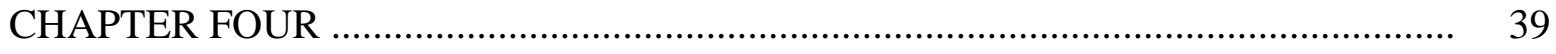

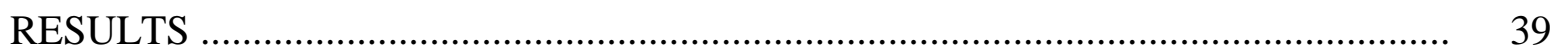

Demographics of Study Participants ................................................................ 39

Training and Needle Stick Information .......................................................... 41

Internal Consistency Measures ………........................................................... 42

Hypothesis Tests of Extended Parallel Process Model ......................................... 46

Hypothesis Tests of Safety Climate ……………………………………........ 51

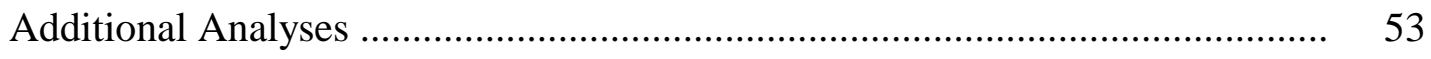

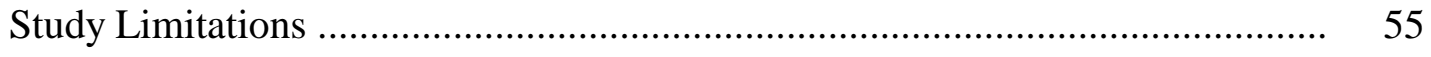

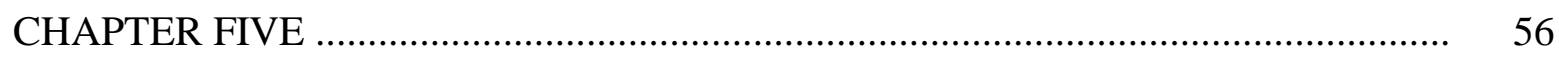

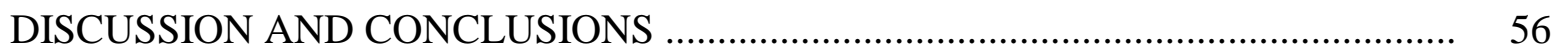


Theoretical Implications .................................................................... 56

Implications for Health Risk Messages ............................................... 60

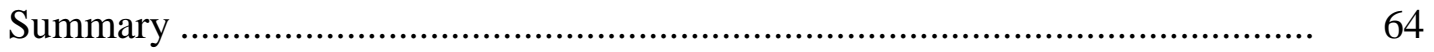

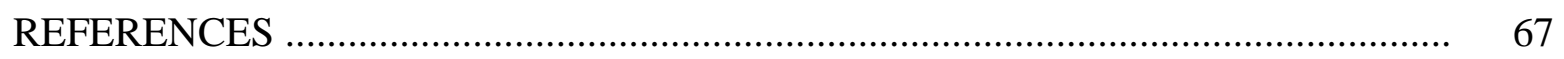

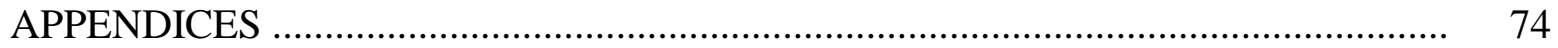

A. Institutional Review Board Materials ................................................... 75 


\section{LIST OF TABLES}

Table 1: Participant Occupations ........................................................................ 39

Table 2: Frequency and Percent of Health Care Workers in Stages of Change .............. 40

Table 3: Needle Stick Reports ....................................................................... 41

Table 4: Cronbach Alpha Values for EPPM Factors ............................................. 43

Table 5: Cronbach Alpha Values for Safety Climate Factors .................................... 44

Table 6: Means of EPPM Factors by Stages of Change ........................................... 45

Table 7: Means of Climate Factors by Stages of Change …................................... 51

Table 8: Mean Comparison of Safety Climate Factors Among Nurses

Versus Other Occupations ................................................................. 53

Table 9: Mean Difference Comparison of HIV/AIDS and Hepatitis B

Fear and Threat Levels Across Stages of Change ....................................... 54 


\section{LIST OF FIGURES}

Figure 1: Means of Fear, Threat, and Fear Control for HIV/AIDS Across the Five Stages of Change ........................................................................... 46

Figure 2: Means of Threat and Efficacy for HIV/AIDS Across the Five Stages of Change

Figure 3: Means of Danger Control Factors (Behavior, Attitudes, and Intentions) for HIV/AIDS Across the Five Stages of Change

Figure 4: Means of Safety Climate Factors Across the Five Stages of Change 


\section{Chapter 1}

\section{Introduction}

Standard precautions were mandated for the purpose of decreasing the risk of blood borne pathogen transmission of diseases, namely human immunodeficiency virus and hepatitis B infections (Centers for Disease Control, 1988, 1991). Standard precautions specify that health care workers are to assume that the blood and body fluids of all patients are infected with bloodborne pathogens and that they should protect themselves accordingly when anticipating patient contact. One of the stipulations of standard precautions is that used needles should not be recapped and should be disposed of in an appropriate sharps container. The rate of needle stick injuries among nurses remains at a high level despite the passage of the Occupational Safety and Health Administration (OSHA) regulations regarding standard precautions in March of 1992. In a study of emergency department staffs at two community hospitals, Henry, Campbell, Collier, and Williams (1994) observed that approximately $40 \%$ of the needles used were disposed of improperly and that more than $35 \%$ of syringes and phlebotomy needles were recapped after procedures were finished. In a study of approximately 1700 health care workers in 3 regions of the United States (Gershon, et al., 1995), 27\% of health care workers reported they were recapping needles that had been contaminated with blood. Henry, Campbell, and Maki (1992) observed emergency department personnel for over 270 hours and found that needles were being recapped $51 \%$ of the time. These studies and several others (Becker, et. al, 1990; Grady, Shortridge, Davis, \& Klinger, 1993; Wong, et. al, 1991) indicate that, despite being mandated by law, compliance with standard precautions among health care workers is at an unacceptable and dangerous level. 
Prochaska (1991) states that over a decade of research indicated that cessation of problem behaviors or adoption of healthful ones is not likely to occur through one trial learning. Prochaska, Redding, Harlow, Rossi, and Velicer (1994a) state that behavior change takes time and requires movement through motivational stages. During the movement through these stages, change requires the use of different processes of change applicable to each stage and the modification of cognitions, affect, and behaviors (Prochaska, et al. 1994a). According to the transtheoretical model (Prochaska, et al. 1994a), people move through a series of five stages to reach a stage of sustained behavioral change: precontemplation, contemplation, preparation, action, and maintenance. Behavior change does not always progress in a linear fashion through the stages. The transtheoretical model allows for relapse or a recycling through earlier stages before successfully reaching the maintenance stage. Proschaska (1994) reports that the transtheoretical model has been applied successfully to twelve problem behaviors including a combination of high risk, addictive, and healthy living behaviors. Interestingly, it seems the transtheoretical model has not been applied in occupational settings.

The success an individual has in moving through the five stages has been attributed to cognitive appraisals with little emphasis on affect. The role that fear might play in moving across the stages of change has not been adequately examined. The Extended Parallel Process Model (EPPM) helps explain the role fear plays in modifying behavior (Witte, 1994). According to the EPPM, fear messages may initiate two appraisals: one regarding the threat and the other regarding the efficacy of the recommended response. One of three responses results from these appraisals: no response, acceptance, or rejection. If the initial appraisal results in the belief that one is not at risk for the health threat or it is perceived that the health threat is not serious, then 
there will be no response to the message. According to the model then, there will be no attitude, intention, or modification of behavior. When threat reaches a certain level, then individuals will make an additional appraisal regarding the efficacy of the recommended response weighed against the perceived strength of the threat (Witte, 1998). At this point, perceived threat is high enough to cause fear. Fear and threat may now both increase due to the heightened effects of each on one another. The EPPM stipulates that individuals become motivated to take some type of action as a result of the increased levels of threat and fear. The two types of action that individuals may engage in are either danger control or fear control responses. Thus, the action chosen by individuals is determined by efficacy perceptions related to the recommended response in averting the threat (Witte, 1998).

Organizational factors are important to consider when examining relationships in occupational settings (Cohen, 1977). Since this study took place in a hospital setting, an examination of safety climate will be included in this study. Safety climate is the set of perceptions held by employees regarding safety aspects of their organization (Zohar, 1980). A poor safety climate exists when upper management lacks a personal involvement in safety activities on a routine basis, safety officers have low status, and there is a lack of promotion of safety activities (Zohar, 1980). Consequently, employees are likely to perceive that management blames poor safety behavior on workers and thus does not consider workplace factors to be significant contributors to poor safety performance (DeJoy, 1985). In a positive safety climate, two-way communication exists between management and employees, top management is personally involved in safety activities and meetings, and emphasis is placed on identifying hazards in the workplace (DeJoy, 1985). 


\section{Significance of the Study}

The role fear plays in decisions regarding health related behaviors such as intravenous drug use has been critically examined (DuPont, 1991; Schottenfeld, O'Malley, \& Abdul-Salaam, 1989; Sherr, 1990), but fear related to occupational task behavior (e.g., needle re-capping and disposal by health care workers) has received little attention. The transmission rate of HIV/AIDS from percutaneous exposure is estimated to be $0.3 \%$ (Marcus, 1988). As of June 1998, there had been 54 confirmed occupationally transmitted cases of HIV of which 46 were due to needle sticks (Centers for Disease Control and Prevention, 1998). Conversely, the transmission rate of Hepatitis B is estimated to be between 6 and 30\%, a possible 18 to 90 fold difference compared to HIV (Hersey \& Martin, 1994). In 1995, it was reported that 400 health care workers contracted Hepatitis B through occupational transmission (Mahoney, Stewart, Hu, Coleman, \& Alter, 1997). With the severe threat of these blood borne diseases, it is important to determine what role fear might play in enhancing or deterring standard precautions (specifically, the nonrecapping of used needles) compliance behavior. This task can be effectively accomplished using a combination of the EPPM (Witte, 1994) and the transtheoretical model (Prochaska, 1994). While the EPPM may be effective in determining if danger control or fear control responses are employed, it is also crucial to know under what conditions they are being used. The transtheoretical model provides a method for measuring a person's "readiness" or stage of change. The combination of behavioral and value-expectancy models has been also proposed by DeJoy (1996). Following his earlier adaptation of the PRECEDE model for workplace behavior (DeJoy, 1986), three groups of factors are proposed to effect workplace behavior: predisposing 
factors (individual characteristics such as fear and threat perceptions), enabling factors (motivational antecedents such as skills, knowledge, efficacy, and barriers), and reinforcing factors (perceived rewards such as performance feedback) (DeJoy, 1996). Such a model has yet to be reported in the literature. This study provides insight into the importance of not only assessing fear levels across stages of change, but also safety climate and other EPPM components when developing occupational safety and health messages and programs.

\section{Problem Statement}

The relationship among the responses of individuals (threat and efficacy), their safety climate perceptions, and position within one of the stages of change (Prochaska et al. 1994a) is the focus of this dissertation. Many occupational behaviors, such as handling used needles often involve a great deal of risk. Fear may be one reason why workers do not want to initiate or fail to initiate a safe behavior when the situation warrants it. An examination of fear, threat, and efficacy levels within the stages of change, and an overall assessment of safety climate, may indicate crucial components needed for effective tailoring of messages or programs for health care workers whose non-recapping compliance behavior has been less than satisfactory.

\section{Research Questions}

1. What is the relationship between self reported fear, threat, and efficacy and health care workers' self reported decisions regarding the behavior of re-capping and disposing of used needles?

2. What is the difference in self reported fear, threat, efficacy levels, and safety climate across the self reported stages of change described by Prochaska et al. (1994a)?

3. What is the relationship between self reported levels of efficacy across the self reported stages 
of change and self reported fear and threat?

4. What is the relationship among self reported safety climate, fear, threat, and efficacy levels ? Hypotheses:

1. Lower self-reported fear level will be associated with self reports of motivational stages later in the precontemplation to maintenance sequence.

2. Lower self-reported threat level will be associated with self reports of motivational stages later in the precontemplation to maintenance sequence.

3. Greater self-reported efficacy levels will be associated with self reports of motivational stages later in the precontemplation to maintenance sequence.

4. Self reports of danger control responses will be significantly greater when participants report being in the action and maintenance stages and self reports of fear control responses will be more prevalent when participants report being in the precontemplation, contemplation, and preparation stages (based on $\mathrm{H} 1$ and $\mathrm{H} 2$ ).

5. Safety climate perceptions will be most positive for those who report using danger control processes.

\section{$\underline{\text { Definitions }}$}

Fear. Fear is an internal and emotional reaction made up of psychological and physiological dimensions that may be aroused when a serious and personally relevant threat is perceived (Witte, 1994).

Threat. A threat is a danger or harm that exists in the environment whether we know it or not. Perceived threat refers to cognitions or thoughts about that specific danger or harm. Perceived threat is made up of two dimensions, susceptibility and severity (Witte, 1994). 
Perceived Susceptibility. Beliefs about one's own risk of experiencing the threat

(e.g., "I'm at risk for tuberculosis because I don't use a respirator") (Witte, 1994).

Perceived Severity. Beliefs about the significance or magnitude of the threat (e.g., "TB infection can lead to death") (Witte, 1994).

Efficacy. Efficacy pertains to the effectiveness, feasibility, and ease with which a recommended response impedes or averts a threat. Perceived efficacy refers to thoughts or cognitions about its underlying dimensions, self-efficacy and response efficacy (Witte, 1994).

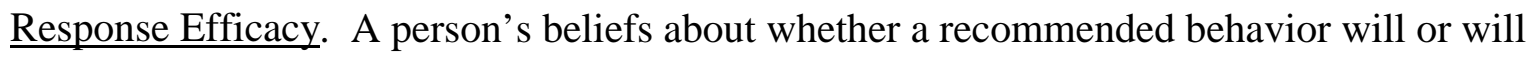
not lead to a given outcome (avert the threat).

Self-Efficacy. A person's beliefs about whether s/he can or cannot perform a recommended behavior (to avert a threat).

Danger Control. A cognitive process eliciting protection motivation that occurs when one believes s/he is able to effectively avert a significant and relevant threat through self protective changes. When in danger control, people think of strategies to avert a threat (Witte \& Allen, 1996).

Danger Control Responses. Belief, attitude, intention, and behavior change in accordance with health message recommendations (Witte \& Allen, 1996).

Fear Control. An emotional process eliciting defensive motivation that occurs when people are faced with a significant and relevant threat, but believe themselves to be unable to perform a recommended response and/or they believe the response to be ineffective. The high levels of fear caused by this condition produce defense motivation resulting in coping responses that reduce fear and prevent danger control responses (Witte \& Allen, 1996). 
Fear Control Responses. Coping responses that lessen fear such as defense avoidance, denial, and reactance (Witte \& Allen, 1996).

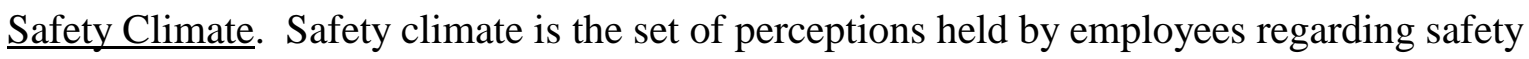
aspects of their organization (Zohar, 1980). 


\section{Chapter 2}

\section{Review of the Literature}

The review of the literature covers: studies that have examined standard precautions training programs (related to needle recapping behavior), the history of studies in fear research, studies that exemplify the role that fear plays in the Extended Parallel Process Model (EPPM) (Witte, 1994), studies that examine the importance of including organizational factors (i.e., safety

climate) in occupational safety research, studies in stages of change research that exemplify the need for affective components, and concludes with a summary as to how gaps in the literature might be filled by the proposed study.

\section{$\underline{\text { Standard Precautions Training Programs (Needle Recapping) }}$}

It seems as if, for the most part, standard precautions training programs have not been very effective in altering non-compliant behavior. Gershon, et al. (1995) conducted a study using a self-administered questionnaire survey of 1,716 health care workers from three geographically distinct hospitals. The purpose of the study was to assess compliance rates among health care workers. The stratified convenience sample included physicians, nurses, technicians, and phlebotomists. Gershon, et al. (1995) reported that those health care workers who received at least one hour of training on blood borne pathogens were more likely to be compliant (26\%) than workers receiving no training (15\%). This finding is significant, yet it also shows that $74 \%$ of those who received one hour of training were non-compliant regarding standard precautions. Compliance was measured according to an 11-item scale that assessed all facets of standard precautions from wearing protective gloves to not recapping used needles. Interestingly, Gershon, et al. (1995) reports that the lowest levels of compliance among these health workers when 
examining individual items were wearing of protective eyewear and outer clothing, cleaning up spills, and needle recapping.

In a study that included 402 physicians, nurses, and caregivers who were administered a written survey during scheduled hospital meetings, Becker et al. (1990) examined the relationship between attendance at a voluntary educational program focusing on needle recapping and a new bedside needle disposal system. Becker et al. (1990) found that although $37 \%$ of the staff attended the educational program, the observed frequency of recapping behavior remained unchanged. Becker et al. (1990) further reports that despite in-service education programs and written policies at the hospitals included in the study, almost $50 \%$ believed that needle recapping provided protection for their colleagues, 77\% agreed somewhat with the statement, "Most of my colleagues recap needles," and $34 \%$ reported preferring to recap needles instead of taking an uncapped needle to the disposal box. The most disturbing finding in the study Becker et al. (1990) states is that less than half of those surveyed strongly disagreed with the statement, "I would recap a needle if I know the person has AIDS." A strength of this study is that the selfreported rates of needle recapping were compared to unannounced counts of capped and uncapped needles found in needle disposal boxes. Surprisingly, the percent of recapped needles found in 3 of the 4 hospitals' needle boxes ranged from $20 \%$ to $51 \%$ and roughly corresponded to self-reported rates. Becker et al. (1990) stipulates that it is possible that insufficient attention is being placed on the fact that recapping needles increases the risk of needlestick injuries. This study indicates that rather than exposing themselves to risk, participants actually believed that by recapping needles their colleagues were better protected from infection. Finally, this study indicated that although health care providers were exposed to ample training and hospital policy, 
knowledge, attitude, and behavior appear to be quite important factors to be considered in improving compliance to standard precautions (Becker et al., 1990).

Hersey and Martin (1994) conducted a study of 3,094 health care workers using a selfadministered questionnaire. This study went to great length to assess the impact of non-response on the survey results. Early respondents were compared to later respondents based on the rationale that individuals who responded only to a follow-up (late respondents) would be more similar to non-respondents than to those who participated in response to the initial request (Hersey \& Martin, 1994). No major differences were found between these two groups of respondents. Nearly all of the patient care staff in this study (96\%) reported that they "always" used sharps disposal containers, but patient staff also reported that they often recapped needles after giving injections (55\%) and after drawing blood (45\%) (Hersey \& Martin, 1994). This is important as it indicates that even though compliance was very high with one part of standard precautions (proper needle disposal), another part was being ignored by nearly half the patient care staff (not recapping needles). Hersey \& Martin (1994) also report that 89\% of patient care staff stated they had attended at least one training session in infection control precautions and more than half of those $(51 \%)$ reported attending three or more.

Willy et al. (1990) conducted an anonymous self-administered national survey of 1,784 midwives. The study indicated that $24 \%$ had received one or more needlestick injuries in the past 6 months and that a strong association existed between needle recapping and the occurrence of needlestick injuries. The survey identified several reasons why midwives might not use standard precautions. The third most cited reason (38\%) was that standard precautions were perceived as unnecessary. Willey et al. (1990) defined "compliers" as those midwives who 
reported complying with seven of ten components of standard precautions stated in the survey. "Non-compliers" were those who reported using less than seven of ten of the standard precaution measures. Among the compliers (40\%), one of the most frequently reported non-compliant element of standard precautions was recapping needles. According to the Willey et al. (1990), effective training programs need to focus on emphasizing the risk that is present in the workplace, not just understanding how bloodborne pathogens are transmitted.

The findings from these studies clearly indicate that increasing compliance to standard precautions (specifically, not recapping needles) takes more than basic in-service education (knowledge and awareness programs). Incorporating affective and specialized (e.g., according to "readiness" to comply) components in training programs might go a long way in increasing standard precautions compliance.

\section{$\underline{\text { Fear Research }}$}

The effect that fear has on behavior change has been studied extensively. Fear research has resulted in a myriad of theories that shed light on how fear might affect behavior, but the theories often contain conflicting premises regarding the effect different levels of fear have on behavior change.

The Fear-as-Drive-Model (Hovland, Janis, \& Kelly, 1953) states that people first have to learn to fear a threat. This fear then motivates or drives a person's behavior. The model further postulates that anything that decreases fear is a reinforcer and thus becomes a habitual response to the threat (this can include recommended response messages or defense avoidance). Janis (1967) and McGuire (1968) extended the Fear-as-Drive Model to include a curvilinear relationship (Non-monotonic model) between fear arousal and persuasion. Their model states 
that as fear increases, the effectiveness of a message increases to a certain point and then drops off (too much fear would result in maladaptive outcomes such as reactance and defense avoidance). In their review of early fear research, Ray and Wilkie (1970) argue that studies finding a positive relationship between fear and intention/behavior probably involved lower fear appeal levels than those resulting in a negative relationship between fear and intention/behavior. This reconciliation of discrepant findings might appear to be valid, but Sternthal and Craig (1974) argue that since the absolute fear levels cannot be measured in the studies Ray and Wilkie (1970) refer to, the nonmonotonic relationship is still questionable. However, studies did follow that attempted to validate absolute fear levels and use them as independent measures in experimental studies. In a study of 926 sixth, seventh, and eighth grade students aimed at assessing dental hygiene behavior, Ramirez and Lasater (1976) tested the curvilinear relationship between fear arousal and persuasion. In this pre-post test study, four communication intervention conditions were presented using slides and a taped voice accompaniment: (1) high fear followed by recommendations, (2) moderate fear followed by recommendations, (3) low fear followed by recommendations, and (4) recommendations only. The research hypothesis was that those in the moderate fear group followed by the recommendations only group would be more likely to follow recommendations than those in the other conditions. Participants completed questionnaires and had their teeth tested for cleanliness both pre and post intervention. Anxiety levels were measured immediately following presentations of messages and were significantly higher for the high fear group than for the three other groups (this served to validate 3 different levels of fear). Contrary to the curvilinear hypothesis, the results of this study indicated that all the messages had a significant effect on toothbrushing behavior. Also, results indicated that the 
communications for those in the high and moderate fear conditions were more effective than for those in the low fear condition. Also, those in the high fear condition had a significantly higher perceived efficacy level than those in the other conditions. These results then, do not tend to support the inverted-U relationship (non-monotonic) between fear and change of attitude as suggested by Janis (1967) and McGwire (1968).

In their critical review of the fear literature, Beck and Frankel (1981) reject the drive models as an accurate depiction of the effect of fear on behavior change for two reasons: there is little to no research evidence that low to moderate fear levels lead to greater persuasion than high fear levels and there is also no evidence that people accept health recommendations primarily to reduce fear level. Beck and Frankel (1981) further state that the drive models can be dismissed as viable explanations because their sequencing of fear arousal and arousal reduction has not been shown to be a precursor to protective behavior in response to a health threat.

Leventhal (1970) also questioned the efficacy of the curvilinear drive model and consequently developed the Parallel Response Model. This model stipulates that when people are exposed to a threatening message their response can either be cognitive or emotional. Two separate and partially independent information processing systems produce these reactions (Leventhal, Safer, \& Panagis, 1983). The cognitive process serves two functions: generate a clear perception of the health threat and generate plans for coping with the threat. The emotional response (fear) is often readily stimulated by health threats and is independent of cognitive processes (Leventhal et al., 1983). It is important to note that fear can both interact positively and negatively with cognitive processes. It is most likely that emotions and cognitions will interact in ways that are mutually interfering or mutually facilitating (Leventhal et al., 1983). Mutually interfering might mean that 
smokers would avoid getting $\mathrm{x}$-ray screening if they fear that $\mathrm{x}$-rays might lead to the diagnosis of cancer. Mutually facilitating might mean that people get yearly flu shots to avoid the dire consequences of getting a severe case of the flu. Leventhal et al. (1983) also state that fear diminishes rapidly so these reactions are most likely to occur soon after arousal when fear is strongest and cognitions may become stronger over the long term because the representation is more concrete in nature. In a study that examined fear perceptions regarding tetanus inoculations, Leventhal, Singer, and Jones (1965) gave 148 Yale University seniors a public health pamphlet to evaluate. There were four experimental conditions $(2 \times 2$ experimental design) that incorporated two levels of fear (high vs. low) and two levels of information on the availability of the recommended action (specific vs. general). Questionnaires included items that assessed attitudes, intentions, and behaviors regarding tetanus inoculation were filled out by the respondents. Results indicated that high fear subjects had more positive attitudes towards tetanus inoculations and had greater intentions to receive tetanus inoculations. However, regardless of fear level, those who were given specific information about the recommended response were more likely to actually get inoculations. Leventhal et al. (1965) state that, although it appears a specific recommended action was sufficient to motivate participants to get inoculations, a followup analysis indicated that some level of fear must be present whether low or high. In a later review of this study and two others with near identical results (Leventhal, Jones, \& Trembly, 1966; Leventhal, Watts, \& Pagano, 1967), Leventhal et al. (1983) state that all 3 studies support the basic premises of the Dual Process Model (i.e., the Parallel Process Model) that fear and cognitions are processed separately, but may interact to effect responses. Finally, inherent in the research of Leventhal and colleagues is the consistent finding that fear is related to decisions 
about utilizing recommended behaviors.

Protection Motivation Theory deviates from the Dual Process Model in that it emphasizes the cognitive versus emotional appraisals individuals engage in when making preventive health decisions. Initially, Protection Motivation Theory (Rogers, 1975) stipulated that a fear appeal communication initiates cognitive appraisals regarding the severity of the event, the probability of the occurrence of the event, and the efficacy of a recommended response to avert the threat. These appraisals mediate the persuasive effects of the fear message by arousing protection motivation, which in turn, leads to behavior to protect oneself from the threat (Maddux \& Rogers, 1983). A revised version of Protection Motivation Theory (PMT) was proposed (Rogers, 1983) that incorporated self-efficacy as the fourth mediating process. Self-efficacy is the critical component of a theoretical framework examined by Bandura (1977) for analyzing changes achieved in fearful and avoidant behavior. Bandura (1977) states that the strength of people's convictions in their own effectiveness to perform a given task (i.e., self-efficacy) is likely to effect whether they will attempt to cope with given situations. Bandura (1977) also states that an outcome efficacy component is important within this framework. Outcome expectation is a person's estimate that a given behavior will lead to certain outcomes (Bandura, 1977). Maddux and Rogers (1983) state that self-efficacy was added to PMT so that it could be stated in more general terms and applied not only to fear appeal research, but to other attitude change research as well. In a study that consisted of surveying 153 cigarette smoking graduate students about their attitudes and opinions about cigarette smokers and the development of educational materials, Maddux and Rogers (1983) hypothesized that self-efficacy, probability of occurrence, coping response efficacy, and outcome severity (using a 2 × 2 × 2 × 2 design) would 
produce main effects for intentions to adopt the recommended behavior (in this study, reduced or elimination of smoking). Significant main effects resulted for both self-efficacy expectancy and coping response efficacy in the predicted direction on intentions to stop smoking. Maddux and Rogers (1983) further state that not only did self-efficacy expectancy prove to be a valuable addition as a fourth component of PMT, it was the strongest predictor of behavioral intention and was significantly related to two other major components in the model: probability of a threat's occurrence and coping response efficacy. This study found a marginally significant difference of fear levels among those in the high-severity essay group versus control, but fear levels were not significantly different among any of the other groups. Fear was not related to behavioral intentions. Rogers (1983) states that fear affects message acceptance only indirectly through the threat appraisal component of severity.

The Subjective-Expected Utility Model (Sutton, 1982) states that people choose a behavioral response based on its subjective-expected utility (SEU). An SEU is a value that people attach to possible outcomes and the perceived probability that a choice will lead to the outcome. Considering this approach, it is most useful to regard an individual's decisions as based on a consideration of the perceived consequences of the available courses of action (Sutton \& Eiser, 1984). For example, a smoker receives a message on how smoking cigarettes may lead to lung cancer. Two choices are obvious, to quit smoking or continue. Trying to quit smoking may lead to either success or failure that in turn may lead to lung cancer (two SEUs). The other alternative, to continue smoking has an SEU related to getting lung cancer. Therefore, the decision to try and quit smoking is based on three factors: (1) the utility, or degree of seriousness, associated with lung cancer, (2) the probability difference, or the reduction in risk of cancer as a 
result of quitting, and (3) the subjective probability of success, or the confidence one has that quitting smoking will avert the outcome of cancer (Sutton \& Eiser, 1984). These three factors are very similar to those discussed previously in protection motivation theory; severity of disease, outcome efficacy, and self efficacy. The subjective utility model as stated gives no role to fear as a mediator of communication and attitudes/behavior; it is thought to be a byproduct of thoughts about a threat. In a study by Sutton and Eiser (1984), a subjective utility model was tested using the three factors mentioned above (utility, probability difference, and subjective probability), but fear was also measured to see if it had clear and independent effects on intentions. Two concurrent and similar studies were conducted that included samples of 138 and 157 volunteers. Each sample was broken into six groups varying from 20 to 30 people. Groups were alternately assigned to watch a videotape about smoking or alcoholism (the alcoholism tape served as control for first group; a seat belt video was used as control for the second study group). The video for the experimental group featured a personal interview with a man dying of lung cancer from smoking and an interview with a physician who discussed the risks of smoking to health. Subjects completed a short self-report questionnaire just before viewing the video and a longer version of the questionnaire about a week following viewing the videotape. Subjects who indicated they were smokers were sent a follow-up questionnaire three months later. Subjective utility, probability difference, and the subjective probability of success were all found to have an effect on intention and behavior related to quitting smoking. Contrary to predictions of the study, fear had a quite significant direct effect on intention to quit smoking with no indication of a curvilinear effect as the non-monotonic model stipulates (Sutton \& Eiser, 1984). Interestingly too, the total effect of the film on intention was determined to be mediated almost completely 
through fear. In their discussion, Sutton and Eiser (1982) state that both danger control (3 factors) and fear control processes (Leventhal, 1970) appear to be active. Sutton and Eiser (1982) close in posing the question as to how these two processes might interact to determine a person's response to a fear appeal message.

As is well illustrated above, the area of fear research has resulted in many conflicting findings regarding the role fear plays in behavior change. The Extended Parallel Process Model addresses several of the conflicts of past fear research by using a combination of the theoretical constructs previously discussed.

The Extended Parallel Process Model (EPPM)

The EPPM is an extension of the Parallel Process Model (Leventhal, 1970) and uses components from PMT (Rogers, 1983). Like the Parallel Process Model, the EPPM stipulates that when individuals are exposed to a threat they may engage in either danger or fear control responses. Unlike protection motivation theory (Rogers, 1973), the EPPM provides a better explanation of how fear plays a role in message processing. Precisely, the EPPM specifies the variables and processes that lead to message rejection (fear control processes) while PMT does not. The EPPM is comprised of threat, efficacy, fear, danger control, and fear control components. Threat is made up of two components, severity (e.g., "How harmful is tuberculosis?") and susceptibility (e.g., "How likely am I to get tuberculosis?”). Threat is appraised in an additive manner (perceived severity + perceived susceptibility) when an individual is confronted with a fear message (Witte, 1998). Perceived efficacy is made up of response efficacy and self-efficacy. Response efficacy refers to whether an individual believes a recommended response is effective (e.g., "Is wearing a respirator effective in preventing 
tuberculosis transmission?") and self-efficacy refers to whether an individual believes he/she is capable of performing the recommended response (e.g., "Am I capable of wearing a respirator consistently?"). As was the case for threat, efficacy is measured in an additive manner (perceived response efficacy+perceived self-efficacy). When perceived efficacy levels exceed those of perceived threat, individuals will engage in danger control processes (Witte, 1998). Witte (1998) also notes that there is a critical point (i.e., "threshold level") where perceived threat exceeds perceived efficacy and individuals engage in fear control processes. At this time, individuals are ignoring thoughts of threat and efficacy and only focusing on how to control their fear. Individuals may think that the recommended response is too difficult, too costly, takes too much time, or feel it may just not work. Fear control responses include reactance, denial, and defensive avoidance and are directly related to fear (Witte, 1998).

An important facet of the EPPM is that an affective construct (fear) is included. Witte (1992a) states that in both the Parallel Process Model (Leventhal, 1970) and the Expectancy Value Theories (Rogers, 1983; Sutton, 1982) fear is neglected and cognitions are overemphasized. Fear is an important concept to consider in behavior change programs. In a study that used a random sample of farmers by county in the state of Texas, 50 face-to-face interviews, 48 telephone interviews, and 177 direct mail questionnaires were completed (Witte et al., 1993). The study sought to examine farmers' threat, fear, and efficacy perceptions related to farming accidents. Witte et al. (1993) found that those farmers who engaged in fear control (high level of denial regarding threat of farming accidents) did not feel threatened (they controlled their fear by denying a threat existed). The implications are that the denial of a threat within this group would result in the need for a vastly different method of communication (of a 
recommended response) than persons who were engaged in danger control behavior. In a longitudinal experimental study of 115 undergraduate college students and their perceptions about HIV/AIDS, Witte (1994) found that fear was directly related to fear control responses, but unrelated to danger control responses except when mediated by perceived threat under a high efficacy condition. This finding suggests that fear is related to protective behavior, but only when a person feels very confident that the protective behavior can be performed and that the behavior is effective in averting the threat. It should be noted that although fear was unrelated to protective behavior, it was directly related to intentions to protect oneself against HIV/AIDS. In a meta-analysis study, Witte and Allen (1996) found that the greater the fear and perception of risk (susceptibility), the more persuasive a fear appeal was. Overall, it was found that high levels of fear produced a greater degree of reactions than low fear levels and that the greater the fear level the greater the danger control and fear control responses (Witte \& Allen, 1996). Finally, danger control responses were found to be inversely related to fear control responses, which suggests that individuals engage in either one of the processes, not both (Witte \& Allen, 1996).

Consistent with other fear research, perceived efficacy has been found to be significantly related to positive outcomes in research studies utilizing the EPPM framework (Witte, 1994). In the study of 115 undergraduate students mentioned previously, perceived efficacy was found to be significantly related to attitudes, intentions, and behavior regarding protecting oneself from HIV/AIDS, but unrelated to fear control responses such as denial or reactance (Witte, 1994). Perceived efficacy was also found to be related to attitudes, intentions, and behavior regarding the use of safety measures in the Texas farmers' study also mentioned previously (Witte et al., 1993). The EPPM closes crucial gaps in the fear research literature. Unlike the models 
mentioned previously, it provides an explanation as to why fear appeal messages are rejected. Most importantly, the EPPM defines the role of fear in a theoretical framework.

\section{$\underline{\text { Safety Climate }}$}

Within occupational settings, studies have shown that organizational factors may play a role in determining workers' attitudes, intentions, and behavior. Organizational climate can be measured by looking at structural properties of the organization (e.g., size, systems complexity, and leadership style) (Porter \& Lawler, 1965) and perceptions held by employees regarding their work environment (Schneider, 1973). Zohar (1980) conducted a study that adopted the latter interpretation of organizational climate. Zohar (1980) used characteristics of low versus high accident companies to develop the dimensions of safety climate. The most consistent characteristics found were that low accident companies had a strong management commitment to safety, top management was personally and routinely involved in safety activities, safety matters were a high priority in company meetings, safety officers had higher status than high accident companies, and safety training was integral in new workers' training programs (Zohar, 1980). In a study of 400 workers from 20 factories in Israel, Zohar (1980) used a 40-item self-report questionnaire that included 8 dimensions of safety climate. Safety inspectors were used to rank the participating companies according to their safety practices and accident prevention programs. An analysis testing the correlation between the rankings and climate scores was conducted. The strong correlations that resulted were an indication of the validity of the safety climate questionnaire (Zohar, 1980). Zohar (1980) concluded that a change in management attitudes and commitment to safety are prerequisites to improving safety behavior in industrial organizations.

Brown and Holmes (1986) tested the validity of the safety climate structure proposed by 
Zohar (1980). Using a confirmatory factor analysis, they found that the model was not supported by data collected on American production workers. Brown and Holmes (1986) developed a three factor safety climate measure (risk perception, management concern for worker safety, and management action regarding worker concern) from American worker data and tested it between groups of accident versus no accident employees. Significantly different perceptions of safety climate resulted between the two groups. This study indicated that safety climate perceptions are reliable indicators of a company's safety with the caveat that only three dimensions are needed. Dedobbeleer and Beland (1991) further substantiated the Brown and Holmes (1986) threedimensional model in a study of 272 construction workers. Interestingly, Dedobbeleer and Beland (1991) also found that a two-dimensional model was adequate to describe safety climate. This two factor model included the dimensions of both management and workers' safety perceptions ( 5 items for management factor; 4 items for worker factor). The results indicate that safety policies in the construction setting should address both managment and workers' safety concerns. Hoffman and Stetzer (1996) conducted a study to examine factors that influence unsafe behaviors and accidents among 204 workers in a chemical processing plant. The authors hypothesized and confirmed that safety climate, using the Dedobbeleer and Beland (1991) twodimensional model, was associated with fewer unsafe behaviors and accidents among chemical workers. Hofmann and Stetzer (1996) conclude in their discussion that only through cross-level investigations (i.e., management and workers) can practitioners adequately identify organizational variables that will influence safety behavior.

Few studies have examined the relationship between safety climate and compliance behavior by health care workers. Michalsen et al. (1993) in a study of 322 physicians from three large 
hospitals found that safety climate was the most significant predictor of compliance with personal protection equipment regulations among physicians. Michalsen et al. (1993) further state that increasing safety in the workplace involves efforts from employees, administrators, and management through peer review, collegial reinforcement, and constant active support. In another study that also found safety climate significantly related to compliance behavior (Gershon, Karkashian, \& Felknor, 1994), safety climate included such characteristics as a commitment to safety by top management, a visible safety program, active safety training programs, accountability for all employees, and an introduction of safer anti-needlestick devices. DeJoy, Murphy, and Gershon (1995) critically examined safety climate perceptions in more than 1400 health care workers using a self-administered questionnaire. A factor analysis of 35 items relating to aspects of safety climate resulted in the formation of eight dimensions of safety climate made up of 23 items. DeJoy et al. (1995) state that the resulting dimensional structure reflects findings in previous studies and provides insight into the types of intervention strategies that might be used to boost compliance to standard precautions among health care workers.

\section{Stages of Change}

As has been mentioned previously, there are five stages of change described in the transtheoretical model (Prochaska et al. 1994a). McConnaughy, Prochaska, and Velicer (1983) state that the five stages are not discrete (they can also be measured continuously using a 32-item measure), but deeming them so serves to make the stages distinct and consecutive for the purpose of measurement. Several studies testing behavior change programs and using stages of change as a measurement tool have utilized the 5-item algorithm. Dijkstra, De Vries, and Bakker (1996) examined smoking cessation behavior among 275 individuals in the Netherlands. The 5-item 
algorithm for stages of change was used and resulted in clear and significant differentiation among the dependent measures. The authors reported that self-efficacy differed across the five stages and that valuable insight for cessation programs could be gained from determining the varying levels of pros and cons of quitting smoking found across the five stages. Marcus, Eaton, Rossi, and Harlow (1994) used the stages of change model to determine the prevalence of readiness to exercise among 698 male and female employees at four Rhode Island work sites. The results of this study indicated that an individual's level of physical activity could be predicted, in part, by knowing their stage of readiness and self efficacy for exercise. In their effort to develop a comprehensive model for behavior change, Prochaska et al. (1994b) examined the stages of change model across 12 health problems, ranging from sunscreen use to quitting cocaine. Five of the behaviors examined involved quitting negative practices (e.g., smoking cessation) and seven of the behaviors involved the acquisition of positive behaviors (e.g., seeking mammography screening). Additionally, the 12 problem behaviors differed dramatically in their frequency of occurrence (i.e., smoking is daily and mammography screening is yearly) and included both legal and illegal behaviors, public and private actions, and socially acceptable and unacceptable actions (Prochaska et al., 1994b). Despite this broad range of problem behaviors, the 5-item algorithm of stages of change was successful in delineating individuals within the behavior change process. Rakowski, Fulton, and Feldman (1993) interviewed 676 women by telephone as part of a study regarding early detection of breast and cervical cancer. The questions of interest centered around the stages of change in seeking mammography screening. The authors found that as one proceeded through the stages of change, decisional balance (pros and cons of adopting a new behavior) became more favorable. Significant differences existed in 
8 of the 10 paired comparisons among the stages. Clearly, the 5-item algorithm was useful in determining behavioral readiness to change. This 5-item algorithm (e.g., precontemplating not recapping needles, contemplating not recapping needles, preparing to not recap needles, not recapping needles, and maintaining the behavior of not recapping needles) is far better than a dichotomous distinction (e.g., recapping versus not recapping needles). Prochaska, Norcross, and DiClemente ( 1994c) report that fewer than 20 percent of a problem population are prepared for action at any given time, yet 90 percent of behavior change programs currently in place are designed with this 20 percent in mind. This means that 80 percent of individuals in behavior change programs are not properly targeted by the design of the program. The ramifications of using a dichotomous grouping versus a five stage grouping were evident in a study examining smokers and their efforts to quit. Data indicated that twice as many contemplators took action to quit versus those in the precontemplation stage and nearly twice as many of those in the preparation stage quit smoking for at least 24 hours than did those in the contemplation group (Prochaska, 1991). Prochaska, (1991) goes on to say that treating the individuals in these stages the same is ludicrous, but that is exactly what we do in using the traditional dichotomous definition of change.

Like the fear and threat research that eventually emerged with a self-efficacy component, stages of change research also includes self-efficacy as an important variable to consider in behavior change. Prochaska, DiClemente, Velicer, Ginpil, and Norcoss (1985) studied 866 adults from Rhode Island and Texas who volunteered to participate in a smoking cessation program in response to newspaper advertisements. Among other dependent factors, a measure self-efficacy for smoking avoidance was administered. Self-efficacy was found to be a 
significant predictor of those moving from contemplation to action and from action to maintenance (Prochaska, DiClemente, Velicer, Ginpil, \& Norcoss 1985). In a study that examined the process of smoking cessation for 1467 individuals placed in the precontemplation, contemplation, and preparation stages of change using the 5-item algorithm criteria, DiClemente et al. (1991) found that self-efficacy factors differentiated among all three stage groups. The authors further state that self-efficacy is a major component in confirming stage differences among smokers. In a study of 191 adult volunteers willing to respond to a questionnaire about their problem smoking behavior, Snow, Prochaska, and Rossi (1992) found significant differences in self-efficacy to quit smoking between individuals in the precontemplation, and the contemplation and preparation stages. According to the literature, self-efficacy seems to be a powerful predictor of movement through the stages of change.

Stages of change research has also included measurement of the "pros" and "cons" of adopting behavior. Decisional balance (pros and cons of adopting a new behavior) represents the process of weighing relevant choices regarding decisions about changing behavior. Janis and Mann (1977) state that sound decisions involve weighing all pertinent information on what they call a decisional "balance sheet." The pros and cons are then considered accordingly. In their conflict theory approach of decision making, Janis and Mann (1977) contend that both individuals and their reference groups are taken into account when making sound decisions. In a study that assessed the stages of change and the decisions made for the prevention of pregnancy, sexually transmitted diseases, and AIDS, Grimley, Riley, Bellis, and Prochaska (1993) based the development of the pros of contraceptive use on concepts such as protection from pregnancy/diseases, partner's reaction to use, ease of use, availability, cost, and perceived 
effectiveness. The development of the cons were based on such concepts as potential side effects, a partner's negative reaction, distrust of certain methods, and hassles associated with various methods. These items were then reviewed by trained judges who were familiar with the decisional balance model. Only items that had $100 \%$ agreement by all three judges were retained. Several other studies have used a similar model of decisional balance ( DiClemente et al. 1991; Dijkstra, De Vries, \& Bakker, 1996; Marcus, Rakowski, \& Rossi, 1992; Prochaska et al. 1994b; Rakowski, Fulton, \& Feldman, 1993). Findings related to decisional balance measures in the aforementioned studies consistently resulted in findings that pros of adopting a new behavior significantly outweigh cons as one progresses through the stages of change. Missing in the decisional balance formula among these studies is the assessment of negative affect or fear as a factor effecting behavior change.

\section{$\underline{\text { Summary }}$}

There is ample literature indicating that standard precautions training programs are not adequately addressing the problem of needle recapping with the standard precautions regulations. Despite the passage of the OSHA regulation in 1992 that needles should not be recapped, evidence to the contrary exists. The literature exemplifying this problem has utilized self-report measures and observations of actual needle recapping behavior among health care workers. Additionally, the literature reports of studies that utilized counts of recapped and un-recapped needles in sharps disposal boxes to determine regulation compliance rates. This literature is consistent in pointing out that current training programs are inadequate. Successful training programs will be those that not only focus on knowledge and awareness, but also highlight the clear risk of disease that health care workers face by recapping needles. 
The fear literature has evolved tremendously over near a half decade of research. Many theories have resulted; some directly conflict with each other, while many build upon constructs in previous research. Conflicts exist among those who believe in a monotonic model (as fear increases so does the likelihood of message acceptance) and those who believe in the nonmonotonic model (a curvilinear relationship that states mid-range fear messages are most effective). Although a controversy, it seems that the monotonic model is more generally accepted. Leventhal (1970) led fear research in the development of the Dual Process Model. Basically, this model stipulates that two processes are involved when a person is presented a fear inducing message: a cognitive process and an emotional arousal process. This dual process framework was confirmed in studies by Leventhal and colleagues (Leventhal et al., 1966; Leventhal et al., 1967; Leventhal et al., 1983). This framework led to the development of the Protection Motivation Theory (Rogers, 1975; Rogers, 1983) that focused on three cognitive mediating processes that occur as individuals decide how to cope with a fear inducing message. Later, Protection Motivation Theory was modified to include a fourth mediating process; selfefficacy. Maddux and Rogers (1983) state that by incorporating self-efficacy, a more comprehensive model is offered. The Extended Parallel Process Model is a culmination of previously developed models in fear literature. It is an extension of Leventhal's Parallel Process Model (1970) and incorporates the cognitive mediating processes of threat and efficacy from Protection Motivation Theory (Rogers, 1983). Most critical to the current study is that the EPPM stresses the important role that fear plays in both message acceptance and message rejection. Witte has critically examined the role of fear for numerous preventive health issues (Witte, 1992b; Witte, 1992a; Witte, 1994; Witte, 1997; Witte, 1998) and found that fear is indirectly 
related to message acceptance and directly related to message rejection. Although the EPPM literature has examined numerous preventive health behaviors, a gap that exists is the examination of these behaviors in an occupational setting.

Beginning with the first studies in what is now loosely termed "safety climate," organizational variables have consistently been found to be positively related to safe behavior in the workplace. Safety climate has been examined in manufacturing (Zohar, 1980), construction (Dedobbeleer \& Beland, 1991), health care facilities (DeJoy et al., 1995; Gershon et al., 1994) and numerous other work place settings (Hofmann \& Stetzer; Brown \& Holmes, 1986). These studies measured factors such as: employee participation in safety programs, management commitment to safety, management involvement in safety activities, and priority of safety issues in company meetings. Consistent across the broad range of studies was the significant relationship between safety climate and compliance behavior in the workplace.

The Transtheoretical Model (Stages of Change) has been applied to numerous health behaviors. Prochaska and colleagues have used self-report surveys in numerous studies to show that behavior change is a "staged" process, not a dichotomous choice (e.g., "Yes, I will quit smoking” versus “No, I won’t quit smoking”). Variables such as self-efficacy, knowledge, awareness, and pros and cons of initiating a behavior have consistently been shown to differentiate across the five stages of change (precontemplation, contemplation, preparation, action, and maintenance). Also consistent across stages of change research is the development of "profiles" of individuals within each stage. These profiles are made up of the typical processes of change that an individual engages in within a stage such as: consciousness raising, selfliberation, emotional arousal, commitment, and countering (Prochaska et al., 1994c). These 
profiles serve to segment individuals so their movement to the maintenance stage can be made more effective than simply considering individuals to either be engaging or not engaging in the recommended behavior. Clearly missing from stages of change literature, is the close examination of fear and the role that organizational variables play in the behavior change process.

An examination of the EPPM constructs and safety climate factors within the Stages of Change model provides an opportunity to assess attributes (i.e., fear, threat, safety climate) within specific segments of the behavioral change process. Discovering differences among fear, threat, efficacy, and safety climate across the stages of change will provide additional support for the belief that specialized versus generic messages and programs are more effective in altering compliance behavior. 


\section{Chapter 3}

Methods

The purpose of this study was to determine the differences in fear, threat, and efficacy levels across the five stages of change for health care workers who routinely handle needles and/or other sharps. To determine a participant's stage, modified versions of questions that have been validated in research testing the transtheoretical model (McConnaughy et al. 1983) were used. A simple 5-item algorithm placed the participants in one of the five stages of change. This five stage algorithm includes the following definitions for inclusion: (1) precontemplation - "I do not plan on stopping my occasional or frequent recapping of needles," (2) contemplation - "I recap needles, but I am seriously thinking about stopping that in the next 6 months," (3) preparation "I have sometimes stopped recapping needles in the past year and now am seriously planning to stop my recapping behavior altogether in the next month," (4) action - "I do not recap needles now and have not recapped ANY for 0 to 6 months," and (5) maintenance - "I do not recap needles now and have not recapped ANY for more than 6 months."

Fear, threat, and efficacy were assessed using modified versions of questions that have been used extensively in testing the EPPM (Witte, Cameron, McKeon, \& Berkowitz, 1996). Fear has been validated in a study by Mewborn and Rogers (1979) and the threat and efficacy measures have been validated in several studies (Witte, 1992b; Witte et al. 1993; Witte et al. 1996). Each of the following is measured on a 5-point Likert scale ranging from "strongly disagree" to strongly agree." The items did not appear in the order presented here, but were placed randomly throughout the questionnaire. Since blood borne pathogens is such a general term and may not serve well as the threat, the researcher decided to assess perceptions regarding two specific blood 
borne pathogens: HIV/AIDS and Hepatitis B. Hepatitis B has been included because it is considered the major occupational health hazard in the health care industry (Hersey \& Martin, 1994).

Perceived Severity

1. I believe that HIV/AIDS (Hepatitis B) is severe.

2. I believe that HIV/AIDS (Hepatitis B) is serious.

3. I believe that HIV/AIDS (Hepatitis B) is significant.

Perceived Susceptibility

1. I am at risk for getting HIV/AIDS (Hepatitis B).

2. It is possible that I will contract HIV/AIDS (Hepatitis B).

3. It is likely that I will contract HIV/AIDS (Hepatitis B).

$\underline{\text { Fear }}$

1. HIV/AIDS (Hepatitis B) frightens me.

2. HIV/AIDS (Hepatitis B) scares me.

3. HIV/AIDS (Hepatitis B) makes me feel anxious.

\section{$\underline{\text { Self-Efficacy }}$}

1. I am able to not recap used needles and sharps to help prevent myself from contracting HIV/AIDS (Hepatitis B).

2. Not recapping used needles and sharps to help prevent contracting HIV/AIDS (Hepatitis B) is easy to do.

3. Not recapping used needles and sharps to help prevent contracting HIV/AIDS (Hepatitis B) is inconvenient. 
$\underline{\text { Response Efficacy }}$

1. Not recapping used needles and sharps is an effective HIV/AIDS (Hepatitis B) prevention measure.

2. Not recapping used needles and sharps helps to prevent contracting HIV/AIDS (Hepatitis B).

3. Not recapping used needles and sharps minimizes the chance of contracting HIV/AIDS (Hepatitis B).

$\underline{\text { Fear Control (reverse scored) }}$

1. When I hear about needle stick injuries leading to HIV/AIDS (Hepatitis B) infection, I spend additional time thinking about them.

2. News of needle stick injuries leading to HIV/AIDS (Hepatitis B) infection makes me stop and think about my own personal safety.

3. When I hear about needle stick injuries leading to HIV/AIDS (Hepatitis B) infection, it makes me concentrate on using universal or standard precautions.

\section{$\underline{\text { Danger Control }}$}

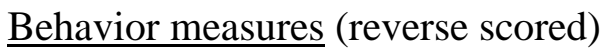

1. I consistently recap needles when performing procedures that require their use.

2. I often recap needles when performing procedures that require their use.

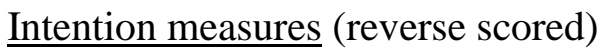

1. I intend to recap needles to help prevent myself from contracting HIV/AIDS (Hepatitis B).

2. I plan to recap needles to help prevent myself from contracting HIV/AIDS (Hepatitis B). 


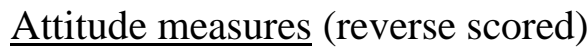

The attitude scale is made up of four 5-point semantic differential scale items:

1. Recapping needles to avoid contracting HIV/AIDS (Hepatitis B) is:

BAD ---- GOOD

UNDESIRABLE ---- DESIRABLE

A BIG DEAL ---- NO BIG DEAL

HARMFUL ---- NOT HARMFUL

\section{$\underline{\text { Safety Climate }}$}

Safety Climate was assessed using 20 items from a study by DeJoy et al. (1995) that surveyed more than 1,000 health care workers (see appendix for copy of the measure). Four items from the original measure were dropped because they had been included to assess susceptibility ( 2 items) and response efficacy ( 2 items; both susceptibility and severity are assessed in the EPPM measure).

\section{$\underline{\text { Demographics }}$}

Gender, age, ethnicity, education, tenure, and hours of standard precaution training in the past year were assessed. In addition, health care workers were asked whether they had ever received a needle-stick injury (if so, when), whether they knew anyone who ever received a needle stick injury (if so, when), and on the average, how many tasks involving needles and sharps did the health care worker perform in a week.

The entire questionnaire was pilot-tested by 10 health care workers working at another nearby hospital. These workers were likely to be comparable to those who participated in the study. 
The pilot test involved sending out the questionnaire, having respondents fill it out, and then provide written comments on the clarity and wording of questions. Follow up phone calls were made to clarify comments. By using this procedure, the researcher was able to revise questionnaire items and help ensure that the intended meaning of the items would be well understood by the actual participants.

$\underline{\text { Sample }}$

The sample of participants was drawn from a tertiary care center in the mid-Atlantic region of the United States. It was a 400-bed facility with 2400 employees that has a same day surgery program, trauma center, long term care program, cardiac care facility, and an aeromedical unit. To produce a significant effect at the $\alpha=.05$ level with power of .80 requires a cell size of 31 (Howell, 1987). Therefore, with 5 cells in the analysis (5 stages of change), at least 155 participants were needed.

The hospital provided a roster of 1018 eligible employees. Inclusion on the roster was determined by whether or not health care workers routinely handled needles and/or sharps (according to safety office training records). This inclusion criterion was also verified by an item on the demographics self-report measure. A random sampling of the roster resulted in the inclusion of 608 employees (59.7\%). The 608 surveys were mailed over a 5-day period through the hospital mailing system to each participant at their work location. Participants were instructed to complete the questionnaire and mail it back through the hospital mail system to the hospital safety office in a self-addressed marked envelope. A box was placed in the safety office so that staff could place study relevant questionnaires separate from other mail. Of the 608 questionnaires sent, 175 were returned. Five were returned unopened because the employee no 
longer worked at the hospital. The resulting response rate was $29 \%$. This response rate is within the normal range of 20 to 30 percent for mail questionnaires according to Dooley (1990). Nine more participants were eliminated from the study because of self reports that they did not work with needles/sharps in their job or because they had neglected to complete crucial information on the questionnaires. Therefore, a total of 161 health care workers made up the sample. An analysis of non-responders would have been useful, but could not be conducted since there was no way of tracking them because the study had been approved by the Institutional Review Board (IRB) on the condition of total anonymity of the respondents.

\section{$\underline{\text { Procedures }}$}

A memorandum of consent was signed and secured from the participating hospital. This letter stated that the hospital approved of the study being conducted by the researcher. As stated above, it was determined by the IRB that a consent form could not be used because of the nature of the data being collected. Therefore, an IRB approved cover letter was enclosed with the questionnaires along with a return envelope. The cover letter explained to eligible participants that their participation would be fully voluntary, that their responses would be kept strictly anonymous, and that their willingness or unwillingness to participate would not in any way affect their job status. Eligible participants were also informed that the study was being done in partial fulfillment of doctoral degree requirements for the researcher.

In hopes of boosting the participation rate, the researcher sent a memo to supervisors, directors, and managers of departments where eligible employees worked. The memo included a brief statement about the study from the hospital safety director, conveyed the purpose of the study, the importance of participation in the study, and attempted to allay any concerns regarding 
anonymity. Once received by the researcher, the questionnaires were numbered sequentially (serving as an ID number) and entered into a spreadsheet data base.

\section{Data Analysis}

Demographic data were analyzed using descriptive statistics and additionally analyzed to determine if any of the demographic variables might assist in segmenting the target audience (e.g., is job related to the EPPM dimensions, stages of change, or safety climate ?). This was accomplished through a means comparison of the dependent measures across demographic categories.

The means of the dependent measures of fear, threat, efficacy, and safety climate were compared across the stages of change using the GLM program (General Linear Models) (SAS, 1996). Multiple comparison tests of the dependent variable means across the stages of change were examined using the Least Squares Means method (SAS, 1990) followed by a Bonferroni adjustment because of its conservative estimation of effects when performing multiple comparisons (Moore \& McCabe, 1989).

Finally, the analysis included a determination of which of the two blood borne pathogens (HIV/AIDS versus Hepatitis B) was perceived as most threatening and frightening. This served to highlight what disease should be the initial focus of compliance campaigns. 


\section{Chapter 4}

Results

This chapter presents the results of a cross-sectional study examining EPPM and safety climate factors across the stages of change. Characteristics of the sample population are presented first, followed by self-reported rates of needle stick variables, internal consistency and reliability test results of EPPM and safety climate factors, an explanation of the results of the research hypothesis tests, and ending with additional tests of variables across the stages of change.

The majority of health care workers who participated in the study were female $(92.5 \%)$, employed as nurses $(57.1 \%)$, and were an average $36.9(\underline{\mathrm{SD}}=9.26)$ years old. Table 1 includes all the occupations represented among health care workers in the study.

Table 1

$\underline{\text { Participant Occupations }}$

\begin{tabular}{lcc} 
Variable & $\underline{\mathrm{n}}$ & $\underline{\%}$ \\
\hline Occupation & 92 & 57.1 \\
Nurse & 40 & 24.8 \\
Clinical or Support Staff & 10 & 6.2 \\
Medical technologist & 8 & 5.0 \\
Lab technician & 7 & 4.3 \\
Surgical technician & 2 & 1.2 \\
Phlebotomist & 2 & 1.2 \\
Other &
\end{tabular}


Table 2

Frequency and Percent of Health Care Workers in Stages of Change

\begin{tabular}{lcc}
\multicolumn{1}{c}{ Stage } & $\underline{\mathrm{n}}$ & $\underline{\underline{\%}}$ \\
\hline Pre contemplation & 33 & 20.5 \\
Contemplation & 14 & 8.7 \\
Preparation & 21 & 13.0 \\
Action & 26 & 16.1 \\
Maintenance & 67 & 41.6 \\
\hline
\end{tabular}

Table 2 shows the percentage of participants within the five stages of change. This table indicates that participants were willing to be at least somewhat honest in their responses, since about $42 \%$ admitted to behavior that is against hospital policy and OSHA regulations (those who reported being in the precontemplation, contemplation, and preparation stages). It should be noted that three of the four stages do not contain the desired amount of participants initially sought, with the contemplation stage the least represented. The implications of this smaller and uneven cell size is that the power to detect a difference at the $\alpha=.05$ level is not equal for all comparisons.

Health care workers reported working an average of $11.46(\underline{\mathrm{SD}}=8.26)$ years with needles and a mean of $45.72(\underline{\mathrm{SD}}=57.00$, Range $=1-500)$ needles handling tasks per week. Health care workers were also asked whether they had received standard precautions training. $79.2 \%$ $(n=126)$ of the participants reported receiving training for an average of 2 hours $(\underline{\mathrm{SD}}=1.95$, Range $=.33-10)$ in the past year and $94.4 \%(n=119)$ of those participants reported that the 
training included the proper handling and disposal of used needles.

Table 3

Needle Stick Reports

Variable

\begin{tabular}{lcc}
\hline & $\underline{\mathrm{n}(\mathrm{yes})}$ & $\underline{\underline{\%}}$ \\
\hline Ever had a needle stick? & 116 & 72.0 \\
Was this first needle stick? & 51 & 44.0 \\
Contaminated with blood? & 44 & 38.3 \\
Needle stick occur within past year? & 42 & 36.2 \\
Know someone who has had a needle stick? & 145 & 90.1 \\
Only one you know who had a needle stick? & 12 & 8.3 \\
The needle contaminated with blood? & 110 & 79.1 \\
Did this incident occur within the last year? & 111 & 77.1 \\
\hline
\end{tabular}

Table 3 includes items asked of the participants regarding their experiences with needle sticks in the workplace. A large proportion (72\%) of participants stated they had experienced a needle stick. Only $44 \%(n=51)$ of those had been stuck once, so it should be noted that $56 \%$ of participants who experienced needle sticks had been stuck more than once. It should also be noted that more than $91 \%$ of participants knew more than one other co-worker who had experienced a needle stick, since only $8.3 \%(n=12)$ reported only knowing one person who had been stuck. Finally, the table illustrates that the majority of those needle sticks reported as happening to others had occurred in the past year $(77.1 \%)$. The high percentage of reported needle sticks contaminated with blood is sobering and indicates that there is a clear risk of blood 
borne disease infection when needle handling procedures are performed.

The EPPM and safety climate factors are individual sets of indicators that reflect underlying constructs (e.g., there are three survey items that represent fear of contracting HIV/AIDS). If the items are properly representing the construct, they should be substantially correlated with each other. Cronbach alpha $(\alpha)$ is used to summarize the reliability of an index. It is a measure of internal consistency of a set of items and ranges from zero (no internal consistency) to unity (perfect internal consistency). The Cronbach alpha test was performed for all the factors in the study to determine if the items within the construct could be used to represent a single index. Table 4 lists all the factors from the Extended Parallel Process Model theoretical construct for both HIV and Hepatitis B items. The Cronbach Alpha levels of the majority of factors used in the analyses were at a reliable level according to Bohrnstedt and Knoke (1982) who state .70 as a cut-off point for acceptability. The threat factors yielded marginally acceptable levels of .65 so both were included in final analyses.

The Cronbach alpha values for the safety climate factors are shown in Table 5. Both the "recapping knowledge" and "work organization" factors were dropped from further analysis because of unacceptably low alpha levels. 
Table 4

Cronbach Alpha Values for EPPM Factors

\begin{tabular}{lc} 
Variable & Alpha \\
\hline HIV Severity & .69 \\
HIV Susceptibility & .65 \\
HIV Threat & .65 \\
HIV Self-Efficacy & .50 \\
HIV Response Efficacy & .79 \\
HIV Efficacy & .74 \\
HIV Fear & .88 \\
HIV Fear Response & .79 \\
HIV Intentions & .77 \\
HIV Attitudes & .83 \\
Hepatitis B Severity & .57 \\
Hepatitis B Susceptibility & .71 \\
Hepatitis B Threat & .76 \\
Hepatitis B Self-Efficacy & .90 \\
Hepatitis B Response Efficacy & .73 \\
Hepatitis B Efficacy & .67 \\
Hepatitis B Fear & .59 \\
Hepatitis B Fear Response & .77 \\
HIV/Hepatitis B Danger Control Response & .97 \\
Hepatitis B Intentions & .76 \\
\hline
\end{tabular}




\section{Table 5}

$\underline{\text { Cronbach Alpha Values for Safety Climate Factors }}$

\begin{tabular}{lc} 
Variable & Alpha \\
\hline Feedback regarding recapping behavior & .74 \\
Management commitment to safety of workers & .75 \\
Personal protection equipment availability & .70 \\
Barriers to safe recapping behavior & .80 \\
Recapping knowledge & .28 \\
Work organization & .25 \\
\hline
\end{tabular}


Table 6

Means of EPPM Factors by Stages of Change

\begin{tabular}{|c|c|c|c|c|c|c|c|c|c|c|}
\hline & \multicolumn{10}{|c|}{ Stage of Change } \\
\hline & \multirow{2}{*}{\multicolumn{2}{|c|}{$\begin{array}{l}\text { Pre-Contemp } \\
\qquad \mathrm{n}=33\end{array}$}} & \multirow{2}{*}{\multicolumn{2}{|c|}{$\begin{array}{l}\text { Contemp } \\
n=14\end{array}$}} & \multirow{2}{*}{\multicolumn{2}{|c|}{$\begin{array}{c}\text { Preparation } \\
\text { n=21 }\end{array}$}} & \multirow{2}{*}{\multicolumn{2}{|c|}{$\begin{array}{l}\text { Action } \\
n=26\end{array}$}} & \multirow{2}{*}{\multicolumn{2}{|c|}{$\begin{array}{l}\text { Maintenance } \\
\qquad n=67\end{array}$}} \\
\hline & & & & & & & & & & \\
\hline Variable & $\underline{\mathrm{M}}$ & $\underline{\mathrm{SD}}$ & $\underline{\mathrm{M}}$ & $\underline{\mathrm{SD}}$ & $\underline{\mathrm{M}}$ & $\underline{\mathrm{SD}}$ & $\underline{\mathrm{M}}$ & $\underline{\mathrm{SD}}$ & $\underline{\mathrm{M}}$ & $\underline{\mathrm{SD}}$ \\
\hline HIV Threat & 4.14 & .43 & 4.03 & .38 & 4.04 & .53 & 3.94 & .58 & 3.85 & .55 \\
\hline HIV Efficacy & $3.60_{\mathrm{a}}$ & .72 & $3.78_{\mathrm{ab}}$ & .53 & $3.85_{\mathrm{ab}}$ & .52 & $3.82_{\mathrm{ab}}$ & .59 & $4.14_{b}$ & .73 \\
\hline HIV Fear & 3.79 & 1.09 & 4.36 & .52 & 3.95 & 1.13 & 3.78 & 1.06 & 3.87 & .91 \\
\hline HIV Fear Res & 2.11 & .80 & 1.90 & .57 & 1.92 & .76 & 2.12 & .80 & 1.88 & .72 \\
\hline HIV Intention & $3.58_{\mathrm{a}}$ & 1.03 & $3.21_{\mathrm{ab}}$ & 1.20 & $3.95_{\mathrm{abc}}$ & .92 & $4.00_{\mathrm{abc}}$ & .80 & $4.22_{\mathrm{c}}$ & 1.04 \\
\hline HIV Attitudes & $3.83_{\mathrm{a}}$ & 1.09 & $4.07_{\mathrm{ab}}$ & 1.15 & $4.14_{\mathrm{ab}}$ & 1.09 & $4.51_{\mathrm{ab}}$ & .72 & $4.57_{\mathrm{b}}$ & .88 \\
\hline HEPB Threat & 3.90 & .47 & 3.85 & .45 & 3.72 & .57 & 3.58 & .48 & 3.66 & .52 \\
\hline HEPB Efficacy & $3.54_{a}$ & .79 & $3.59_{\mathrm{ab}}$ & .52 & $3.90_{\mathrm{ab}}$ & .47 & $3.79_{\mathrm{ab}}$ & .58 & $4.11_{\mathrm{b}}$ & .73 \\
\hline HEPB Fear & 3.66 & 1.15 & 4.05 & .60 & 3.78 & .93 & 3.64 & .96 & 3.63 & 1.01 \\
\hline HEPB Fear Res & 2.45 & .89 & 2.08 & .63 & 2.06 & .62 & 2.32 & .80 & 2.09 & .71 \\
\hline HEPB Intention & $3.62_{\mathrm{a}}$ & 1.05 & $3.46_{\mathrm{ab}}$ & 1.06 & $4.00_{\mathrm{ab}}$ & .76 & $4.00_{\mathrm{ab}}$ & .80 & $4.23_{\mathrm{b}}$ & 1.00 \\
\hline HEPB Attitudes & $3.92_{\mathrm{a}}$ & 1.13 & $3.98_{\mathrm{ab}}$ & 1.24 & $4.29_{\mathrm{ab}}$ & 1.04 & $4.70_{b}$ & .70 & $4.59_{\mathrm{b}}$ & .88 \\
\hline Danger Control & $2.35_{\mathrm{a}}$ & .99 & $2.81_{\mathrm{ab}}$ & .90 & $3.31_{\mathrm{bc}}$ & .80 & $3.98_{\mathrm{cd}}$ & .77 & $4.33_{\mathrm{d}}$ & .84 \\
\hline
\end{tabular}

Note: Means in the same row that do not share subscripts differ at $\underline{p}<.05$ according to the Bonferroni adjustment (Moore \& McCabe, 1989).

Table 6 reports the mean differences of the various EPPM constructs across the five stages of change. These mean comparisons were used to test the five research hypotheses. Since there were ten mean comparisons across the stages for each dependent measure, the Bonferroni adjustment requires a $\mathrm{p}=.005$ for differences to be deemed significant $(.05 / 10$ comparisons $=$ .005). Figures 1, 2, and 3 display data for HIV/AIDS perceptions from Table 6 graphically. Hepatitis B perceptions were not used because graphic displays would be nearly identical. 


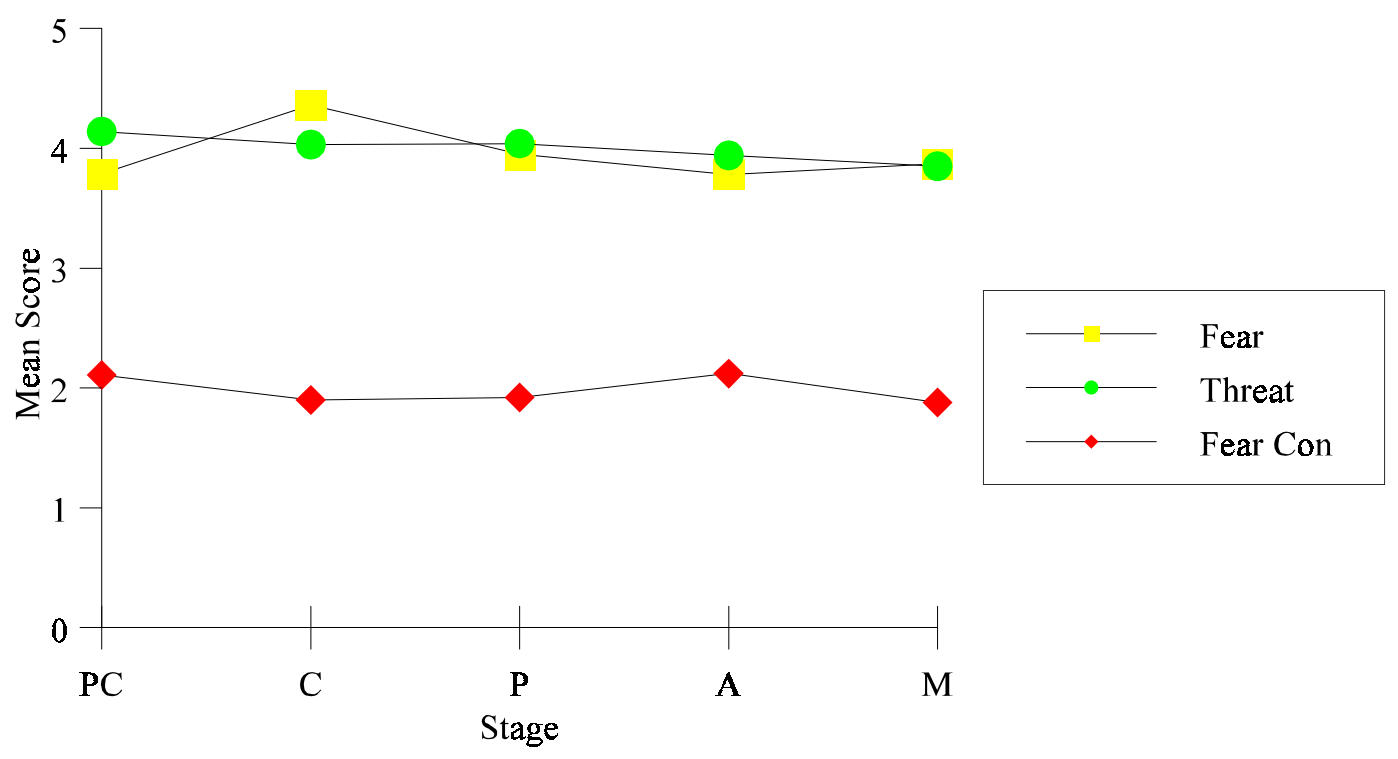

Figure 1. Means of fear, threat, and fear control for HIV/AIDS across the five stages of change.

Hypothesis 1: Lower self-reported fear level will be associated with self reports of motivational stages later in the precontemplation to maintenance sequence.

The mean self-reported values of the fear of HIV/AIDS and Hepatitis B factors were compared across the stages of change. As can be seen in Table 6 and Figure 1, none of the Fear factor means for HIV/AIDS (HIV Fear) or Hepatitis B (HEPB Fear) decreased significantly across the stages.

Hypothesis 2: Lower self-reported threat level will be associated with self reports of motivational stages later in the precontemplation to maintenance sequence.

The mean self-reported threat levels were compared across the stages for the HIV/AIDS (HIV Threat) and Hepatitis B (HEPB Threat) threat factors (see Table 6 and Figure 1). Similar to fear, threat did not significantly differ across the stages, although there was a trend for both threat construct means to decrease across the stages (i.e., a perceived decrease of threat of disease 
across stages).

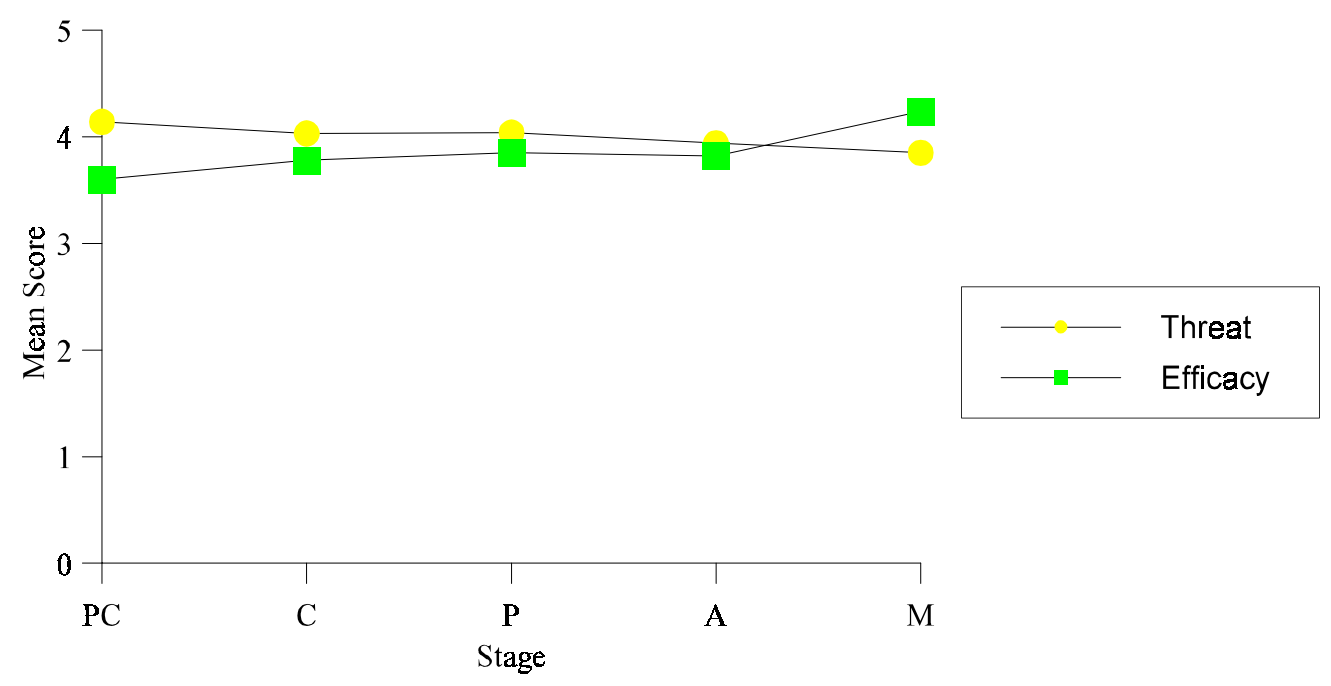

Figure 2. Means of threat and efficacy for HIV/AIDS across the five stages of change.

Hypothesis 3: Greater self-reported efficacy levels will be associated with self reports of motivational stages later in the precontemplation to maintenance sequence.

The mean self-reported efficacy levels of protecting oneself against contracting HIV/AIDS and Hepatitis B were compared across the stages of change. Table 6 indicates that perceived efficacy level regarding not recapping used needles when exposed to HIV/AIDS (HIV Efficacy) for precontemplators $(\underline{\mathrm{M}}=3.60, \underline{\mathrm{SD}}=.72)$ was significantly different, $\underline{\mathrm{t}}(144)=3.68, \underline{\mathrm{p}}=.0003$ than those in the maintenance stage $(\underline{M}=4.14, \underline{\mathrm{SD}}=.73)$. The same relationship for those in the precontemplation $(\underline{\mathrm{M}}=3.54, \underline{\mathrm{SD}}=.79)$ and maintenance stages $(\underline{\mathrm{M}}=4.11, \underline{\mathrm{SD}}=.73)$ was found regarding perceived efficacy level to not recap used needles when exposed to Hepatitis B, t $(150)$ $=3.83, \mathrm{p}=.0002$. This suggests that those in the higher stages of change were more likely to report a greater ability to perform and greater effectiveness of preventive measures to prevent HIV/AIDS and Hepatitis B using non-recapping behavior. 
An important relationship between threat and efficacy was also discovered. Paired comparisons were performed that examined the mean differences between threat and efficacy in each of the stages of change. Those in the precontemplation stage reported significantly higher levels of threat than efficacy for both HIV/AIDS $(\underline{\mathrm{M}}=4.14, \underline{\mathrm{SD}}=.43), \underline{\mathrm{t}}(31)=3.40, \underline{\mathrm{p}}=.002$ and Hepatitis $\mathrm{B}(\underline{\mathrm{M}}=3.90, \underline{\mathrm{SD}}=.47), \underline{\mathrm{t}}(30)=2.15, \underline{\mathrm{p}}=.04$. Conversely, those in the maintenance stage reported significantly higher levels of efficacy than threat for both HIV/AIDS $(\underline{\mathrm{M}}=4.14, \underline{\mathrm{SD}}=.73), \underline{\mathrm{t}}(61)=2.39, \underline{\mathrm{p}}=.02$ and Hepatitis $\mathrm{B}(\underline{\mathrm{M}}=4.11, \underline{\mathrm{SD}}=.73), \underline{\mathrm{t}}(62)=4.08, \underline{\mathrm{p}}$ $=.0001$. Figure 2 is a graphical display of this relationship. This indicates a clear difference in threat and efficacy perceptions among precontemplators and those in the maintenance stage.

\section{Hypothesis 4: Self reports of danger control responses will be greater when participants} report being in the action and maintenance stages and self reports of fear control responses will be more prevalent when participants report being in the precontemplation, contemplation, and preparation stages (based on $\mathrm{H} 1$ and $\mathrm{H} 2$ ).

This hypothesis was tested by examining the factors of Danger Control: HIV/AIDS and Hepatitis B intentions, HIV/AIDS and Hepatitis B attitudes, danger control behavior, and HIV/AIDS and Hepatitis B fear response factors. There were no significant differences across the stages of change for the HIV/AIDS or Hepatitis B fear response factors. See Figure 1 for a graphical display of HIV/AIDS fear control response means across the stages of change. In the case of HIV/AIDS, those in the precontemplation stage $(\underline{\mathrm{M}}=2.11, \underline{\mathrm{SD}}=.80)$ did not significantly differ from those in maintenance $(\underline{\mathrm{M}}=1.88, \underline{\mathrm{SD}}=.72, \underline{\mathrm{t}}(153)=1.43, \underline{\mathrm{p}}=.15)$. Similarly, for Hepatitis $\mathrm{B}$; those in the precontemplation stage $(\underline{\mathrm{M}}=2.45, \underline{\mathrm{SD}}=.89)$ did not differ from those in maintenance $(\underline{\mathrm{M}}=2.09, \underline{\mathrm{SD}}=.71, \underline{\mathrm{t}}(154)=2.26, \underline{\mathrm{p}}=.03)$. Therefore, the research hypothesis 
that fear responses would decrease across the stages of change was rejected.

Mean comparisons of the danger control response behavior factor across the five stages resulted in six significant differences. Significant differences were found between precontemplators $(\underline{\mathrm{M}}=2.35, \underline{\mathrm{SD}}=.99)$ and those in the preparation stage $(\underline{\mathrm{M}}=3.31, \underline{\mathrm{SD}}=.80, \underline{\mathrm{t}}$ $(152)=4.00, \underline{\mathrm{p}}=.0001)$, action stage $(\underline{\mathrm{M}}=3.98, \underline{\mathrm{SD}}=.77, \underline{\mathrm{t}}(152)=7.15, \underline{\mathrm{p}}=.0001)$ and maintenance stage $(\underline{\mathrm{M}}=4.33, \underline{\mathrm{SD}}=.84, \underline{\mathrm{t}}(152)=10.77, \underline{\mathrm{p}}=.0001)$. Contemplators $(\underline{\mathrm{M}}=2.81$, $\underline{\mathrm{SD}}=.90)$ differed significantly from those in the action $(\underline{\mathrm{M}}=3.98, \underline{\mathrm{SD}}=.77, \underline{\mathrm{t}}(152)=3.98, \underline{\mathrm{p}}=$ $.0001)$ and maintenance $(\underline{\mathrm{M}}=4.33, \underline{\mathrm{SD}}=.84, \underline{\mathrm{t}}(152)=5.82, \underline{\mathrm{p}}=.0001)$ stages. Finally, those in the preparation stage $(\underline{\mathrm{M}}=3.31, \underline{\mathrm{SD}}=.80)$ were significantly different from those in the maintenance stage $(\underline{\mathrm{M}}=4.33, \underline{\mathrm{SD}}=.84, \underline{\mathrm{t}}(152)=4.73, \underline{\mathrm{p}}=.0001)$. These findings served to assist in validating the stages of change approach (i.e., the danger control behavior items surveyed the participants own recapping behavior which is what each stage actually represents). As one moves across the stages of change, self-reported levels of compliant non-recapping behavior increases. The only behavior means that did not differ across stages were between precontemplators and contemplators, contemplators and preparers, preparers and those taking action, and those taking action versus those in maintenance. If not for the low number of participants in the contemplation stage, it seems likely 2 of 4 non-differences would have been significantly different. The HIV/AIDS and Hepatitis B intention factor mean comparisons resulted in similar significant differences. For HIV/AIDS, precontemplators $(\underline{\mathrm{M}}=3.58, \underline{\mathrm{SD}}=1.03)$ differed significantly from those in maintenance $(\underline{\mathrm{M}}=4.22, \underline{\mathrm{SD}}=1.04, \underline{\mathrm{t}}(154)=2.98, \underline{\mathrm{p}}=.003)$, as did contemplators $(\underline{\mathrm{M}}=3.21, \underline{\mathrm{SD}}=1.20)$ and those in maintenance $(\underline{\mathrm{M}}=4.22, \underline{\mathrm{SD}}=1.04, \underline{\mathrm{t}}(154)=$ 3.39, $\mathrm{p}=.0009)$. For Hepatitis $\mathrm{B}$, precontemplators $(\underline{\mathrm{M}}=3.62, \underline{\mathrm{SD}}=1.05)$ differed significantly 
from those in maintenance $(\underline{\mathrm{M}}=4.23, \underline{\mathrm{SD}}=1.00, \underline{\mathrm{t}}(155)=2.99, \underline{\mathrm{p}}=.003)$. Contemplators $(\underline{\mathrm{M}}=$ $3.46, \underline{\mathrm{SD}}=1.06$ ) bordered on being significantly different from those in the maintenance stage $(\underline{\mathrm{M}}=4.23, \underline{\mathrm{SD}}=1.00, \underline{\mathrm{t}}(155)=2.72, \underline{\mathrm{p}}=.007)$. These findings indicate intention to not recap more likely later in the stages of change. The HIV/AIDS attitude factor mean comparisons resulted in significant differences between the precontemplators $(\underline{\mathrm{M}}=3.83, \underline{\mathrm{SD}}=1.09)$ and those in the maintenance stage $(\underline{\mathrm{M}}=4.57, \underline{\mathrm{SD}}=.88, \underline{\mathrm{t}}(151)=3.50, \underline{\mathrm{p}}=.0006)$. The Hepatitis B attitude factor mean comparisons resulted in significant differences between the precontemplators $(\underline{\mathrm{M}}=3.92, \underline{\mathrm{SD}}=1.13)$ and those in the action $(\underline{\mathrm{M}}=4.70, \underline{\mathrm{SD}}=.70, \underline{\mathrm{t}}(151)=$ $2.30, \underline{\mathrm{p}}=.003)$ and maintenance stage $(\underline{\mathrm{M}}=4.59, \underline{\mathrm{SD}}=.88, \underline{\mathrm{t}}(151)=3.19, \underline{\mathrm{p}}=.002)$. Figure 3 is a graphical display of the danger control factors for HIV/AIDS across the five stages of change.

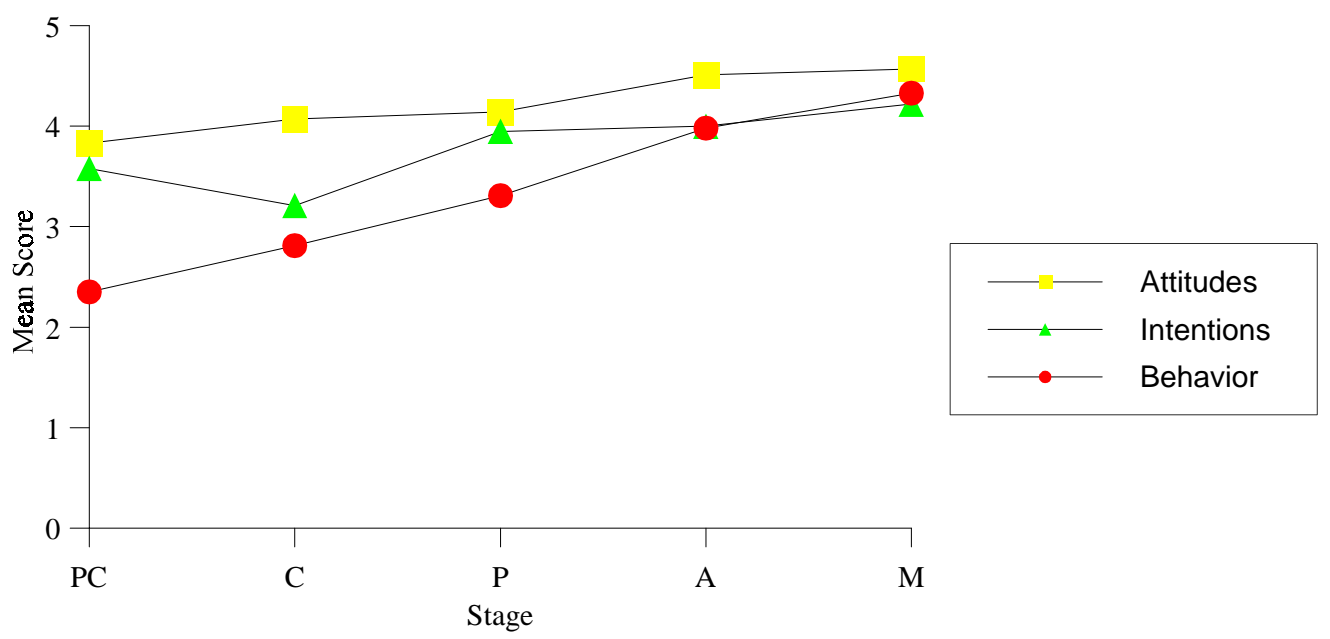

Figure

3. Means of danger control factors (behavior, attitudes, and intentions) for HIV/AIDS across the five stages of change. 
The danger control construct made up of behavior, intentions, and attitudes factors showed clear and consistent increases across the stages of change for both HIV/AIDS and Hepatitis B resulting in acceptance of the research hypothesis that danger control factor means would increase across the stages of change.

\section{Hypothesis 5: Safety climate perceptions will be most positive for those who report using danger control responses}

This hypothesis was tested by examining the four safety climate factor means across the stages of change. Previous results from testing research hypothesis 4 indicated that significantly greater reports of danger control responses (behavior, intentions, and attitudes) were found in the later stages of change and lower reports in the initial stages, so a mean comparison of safety climate factors across stages of change seemed justified. Table 7 indicates that all four of the safety climate factors had significant mean differences across the five stages of change.

Table 7

Means of Climate Factors by Stages of Change

\begin{tabular}{|c|c|c|c|c|c|c|c|c|c|c|}
\hline \multirow[b]{3}{*}{ Variable } & \multicolumn{10}{|c|}{ Stage of Change } \\
\hline & \multicolumn{2}{|c|}{$\begin{array}{l}\text { Pre-Contemp } \\
\qquad \mathrm{n}=33\end{array}$} & \multicolumn{2}{|c|}{$\begin{array}{c}\text { Contemp } \\
\mathrm{n}=14\end{array}$} & \multicolumn{2}{|c|}{$\begin{array}{c}\text { Preparation } \\
n=21\end{array}$} & \multicolumn{2}{|c|}{$\begin{array}{l}\text { Action } \\
\mathrm{n}=26\end{array}$} & \multicolumn{2}{|c|}{$\begin{array}{c}\text { Maintenance } \\
\mathrm{n}=67\end{array}$} \\
\hline & $\underline{\mathrm{M}}$ & $\underline{\mathrm{SD}}$ & $\underline{\mathrm{M}}$ & $\underline{\mathrm{SD}}$ & $\underline{\mathrm{M}}$ & $\underline{\mathrm{SD}}$ & $\underline{\mathrm{M}}$ & $\underline{\mathrm{SD}}$ & $\underline{\mathrm{M}}$ & $\underline{\mathrm{SD}}$ \\
\hline Feedback & $2.44_{\mathrm{a}}$ & 1.11 & $2.79_{\mathrm{ab}}$ & 1.27 & $2.81_{\mathrm{ab}}$ & .78 & $2.68_{\mathrm{ab}}$ & .93 & $3.16_{b}$ & .88 \\
\hline Mgt Commit & $3.42_{\mathrm{a}}$ & .70 & $3.50_{\mathrm{ab}}$ & .67 & $3.55_{\mathrm{ab}}$ & .85 & $3.66_{\mathrm{ab}}$ & .77 & $4.04_{b}$ & .74 \\
\hline PPE & $3.69 \mathrm{a}$ & .82 & $3.77_{\mathrm{a}}$ & .72 & $3.88_{\mathrm{a}}$ & .65 & $4.05_{\mathrm{ab}}$ & .60 & $4.39_{\mathrm{b}}$ & .61 \\
\hline Barriers & $2.96_{a}$ & .77 & $2.93_{\mathrm{a}}$ & .60 & $2.90_{\mathrm{a}}$ & .68 & $2.22_{\mathrm{b}}$ & .66 & $1.85_{\mathrm{b}}$ & .73 \\
\hline
\end{tabular}

Note: Means in the same row that do not share subscripts differ at $\mathrm{p}<.05$ according to the Bonferroni adjustment (Moore \& McCabe, 1989). 
Receiving safety feedback significantly increased between precontemplators $(\underline{\mathrm{M}}=2.44, \underline{\mathrm{SD}}=$ 1.11) and those in the maintenance stage $(\underline{\mathrm{M}}=3.16, \underline{\mathrm{SD}}=.88) \underline{\mathrm{t}}(154)=3.49, \underline{\mathrm{p}}=.0006)$. Similarly, management commitment to safety also significantly increased between precontemplators $(\underline{\mathrm{M}}=3.42, \underline{\mathrm{SD}}=.70)$ and those in the maintenance stage $(\underline{\mathrm{M}}=4.04, \underline{\mathrm{SD}}=.74, \underline{\mathrm{t}}$ $(155)=3.91, \underline{p}=.0001)$. Personal protection equipment availability showed significant increases between precontemplators $(\underline{\mathrm{M}}=3.69, \underline{\mathrm{SD}}=.82)$ and those in maintenance $(\underline{\mathrm{M}}=4.39, \underline{\mathrm{SD}}=.61, \underline{\mathrm{t}}$ $(154)=4.86, \underline{p}=.0001)$, contemplators $(\underline{\mathrm{M}}=3.77, \underline{\mathrm{SD}}=.72)$ and those in maintenance $(\underline{\mathrm{M}}=$ $4.39, \underline{\mathrm{SD}}=.61, \underline{\mathrm{t}}(154)=3.15, \underline{\mathrm{p}}=.002)$, and preparers $(\underline{\mathrm{M}}=3.88, \underline{\mathrm{SD}}=.65)$ and those in the maintenance stage $(\underline{\mathrm{M}}=4.39, \underline{\mathrm{SD}}=.61, \underline{\mathrm{t}}(154)=3.03, \underline{\mathrm{p}}=.003)$ Barriers to compliance significantly decreased between precontemplators $(\underline{\mathrm{M}}=2.96, \underline{\mathrm{SD}}=.77)$ and those in the action $(\underline{\mathrm{M}}=2.22, \underline{\mathrm{SD}}=.66, \underline{\mathrm{t}}(148)=3.84, \underline{\mathrm{p}}=.0002)$ and those in maintenance $(\underline{\mathrm{M}}=1.85, \underline{\mathrm{SD}}=.73, \underline{\mathrm{t}}$ $(148)=7.13, \underline{p}=.0001)$. Barriers to compliance also significantly decreased between contemplators $(\underline{\mathrm{M}}=2.93, \underline{\mathrm{SD}}=.60)$ and those in the action $(\underline{\mathrm{M}}=2.22, \underline{\mathrm{SD}}=.66, \underline{\mathrm{t}}(148)=2.96, \underline{\mathrm{p}}$ $=.004)$ and those in maintenance $(\mathrm{M}=1.85, \mathrm{SD}=.73, \underline{\mathrm{t}}(148)=5.12, \underline{\mathrm{p}}=.0001)$. Lastly, barriers to compliance significantly decreased between preparers $(\underline{\mathrm{M}}=2.90, \underline{\mathrm{SD}}=.68)$ and those in the action $(\underline{\mathrm{M}}=2.22, \underline{\mathrm{SD}}=.66, \underline{\mathrm{t}}(148)=3.16, \underline{\mathrm{p}}=.002)$ and those in maintenance $(\underline{\mathrm{M}}=1.85$, $\underline{\mathrm{SD}}=.73, \underline{\mathrm{t}}(148)=5.73, \underline{\mathrm{p}}=.0001)$. Figure 4 is a graphical display of the safety climate factor means across the five stages of change. Results clearly indicate that positive safety climate perceptions are significantly greater in the later stages of change (i.e, greater among those performing danger control responses), so the research hypothesis was accepted. 


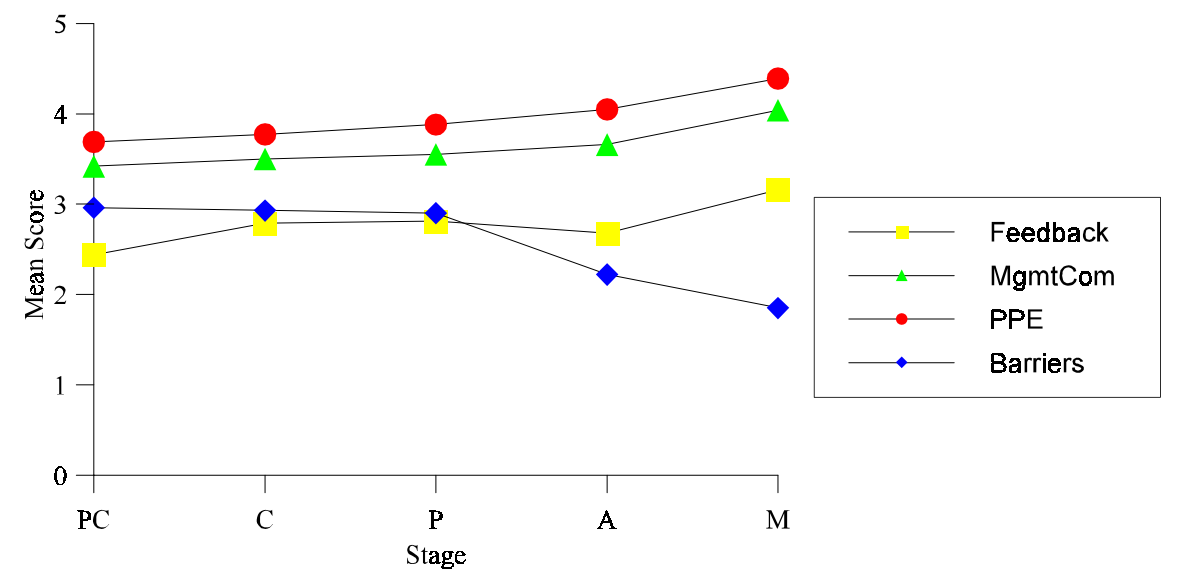

Figure 4. Means of safety climate factors across the five stages of change.

Table 8

Mean Comparison of Safety Climate Factors Among Nurses Versus Other Occupations

\begin{tabular}{lllllllc}
\hline \multicolumn{1}{c}{ Nurses } & \multicolumn{7}{c}{ Others } \\
\hline \multicolumn{1}{c}{ Variable } & $\underline{\mathrm{M}}$ & $\underline{\mathrm{SD}}$ & $\underline{\mathrm{M}}$ & $\underline{\mathrm{SD}}$ & $\underline{\mathrm{t}}$ & $\underline{\mathrm{p}}$ \\
\hline Safety Behavior & 3.32 & 1.16 & 3.97 & 1.08 & -3.54 & .0005 \\
Safety Feedback & 2.59 & 1.00 & 3.21 & .88 & -4.11 & .0001 \\
Management Commitment & 3.47 & .76 & 4.09 & .65 & -5.47 & .0000 \\
PPE Availability & 3.82 & .75 & 4.41 & .52 & -5.91 & .0001 \\
Barriers to Compliance & 2.55 & .87 & 2.13 & .81 & -3.00 & .003 \\
\hline
\end{tabular}

Since a great many of the participants reported being nurses $(57 \%, \mathrm{n}=92)$ and many training programs have been focused on this occupation, it was thought important to examine their perceptions regarding non-recapping of needles and safety climate. Table 8 shows the results of t-tests done to compare the reported means of non-recapping behavior and safety climate items 
among nurses and other occupations. This table clearly illustrates that nurses report significantly lower non-recapping behavior, low rates of receiving safety feedback, lower perceived management commitment to safety, lower perceived availability of personal protective equipment, and greater barriers in complying with safety rules.

Table 9

Mean Difference Comparison of HIV/AIDS and Hepatitis B Fear and Threat Levels Across Stages of Change

\begin{tabular}{lcccccccc}
\hline & \multicolumn{4}{c}{ Fear } & \multicolumn{6}{c}{ Threat } \\
\hline \multicolumn{1}{c}{ Stage } & $\underline{\mathrm{M}}$ & $\underline{\mathrm{SD}}$ & $\underline{\mathrm{t}}$ & $\underline{\mathrm{p}}$ & $\underline{\mathrm{M}}$ & $\underline{\mathrm{SD}}$ & $\underline{\mathrm{t}}$ & $\underline{\mathrm{p}}$ \\
\hline Precontemplation & .13 & .52 & 1.45 & .16 & .24 & .33 & 4.16 & .0002 \\
Contemplation & .23 & .46 & 1.81 & .09 & .18 & .48 & 1.35 & .20 \\
Preparation & .17 & .70 & 1.14 & .27 & .32 & .33 & 4.37 & .0003 \\
Action & .12 & .41 & 1.48 & .15 & .33 & .36 & 4.34 & .0003 \\
Maintenance & .24 & .65 & 2.98 & .004 & .19 & .39 & 3.82 & .0003 \\
\hline
\end{tabular}

Table 9 illustrates the mean differences in perceptions regarding fear and threat of HIV/AIDS and Hepatitis B within the stages of change. The perceived threat of contracting HIV/AIDS was significantly greater than the perceived threat of contracting Hepatitis B in all the stages of change, with the exception of contemplation $(\underline{\mathrm{M}}=.18, \underline{\mathrm{SD}}=.48) \underline{\mathrm{t}}(12)=1.35, \underline{\mathrm{p}}=.20$. Fear of contracting HIV/AIDS was significantly higher only in the maintenance stage $(\underline{\mathrm{M}}=.24, \underline{\mathrm{SD}}=$ $.65) \underline{\mathrm{t}}(65)=2.98, \underline{\mathrm{p}}=.004$. 


\section{Study Limitations}

1. Reporting behavior regarding the recapping of needles may have been perceived as so socially undesirable that it was not possible to accumulate the 31 cases needed in the all five categories of the stages of change. In fact, three stages (contemplation, preparation, and action) did not have the required number, so the analyses do not reflect the power level calculated. However, this lower count in three of the cells did not deter the study from being completed.

2. Participation in the study was voluntary and may have been biased and over represented by those more likely to comply with standard precautions.

3. All the data collected were based on participant self-reports and do not include observations of compliance behavior. 


\section{Chapter 5}

\section{Discussion and Conclusions}

The researcher conducted a cross-sectional survey to determine if the components of the Extended Parallel Process Model (threat, efficacy, fear, fear response, danger control) and Safety Climate factors significantly differed across the stages of change (stage being determined by selfreported non-recapping of used needles behavior). The five hypotheses stated in Chapter 1 provided the analysis framework to assess the differences across the stages change for the EPPM factors and safety climate.

Theoretical Implications

The study results indicated that there were no significant differences across the stages of change for fear or threat. This was somewhat surprising because the EPPM stipulates that fear motivates individuals to take action (in this case it was thought a greater reported non-recapping rate across the 5 stages) that will reduce their fear (Witte et al., 1996). It is important to note though, that the finding of an insignificant decrease in fear across the stages of change may not coincide with EPPM research. Witte (1998) states that according to the EPPM, fear either facilitates (danger control) or interferes (fear control) with the behavior change process. In the current study, fear was unrelated to both fear control and danger control constructs. Additionally, Witte (1994) found that fear reduction was significantly associated with a maladaptive response (fear control), specifically, denial that a threat even existed. The participants in Witte's study actually showed a decrease in their fear level, but for the "wrong" reason (the maladaptive response). In the current study, reports of fear control were consistently low across the stages, so it seems fear control responses did not play a role in reducing participants' high fear levels across 
the five stages of change. Indeed, it may be, as Witte (1994) stipulates, that the high and stable level of fear resulted from a high perceived threat (in this case, that of HIV/AIDS and Hepatitis B that health care workers reported).

One of the main objectives of this study was to determine whether fear played a significant role in health care workers changing their needle recapping behavior. The results indicate that fear may have moderated feelings of threat and led to danger control responses as research in the EPPM has previously indicated (Witte, 1992a) because threat and fear were high, even in later stages of change where efficacy significantly increased. But, this was not the case as fear was not significantly related to danger control behavior in the high threat - high efficacy condition.

The EPPM framework provides a method of assessing fear and examining how it effects change. It is unclear exactly what role fear may play in the stages of change, but the current study does exemplify that fear should not be overlooked in deference to an emphasis on cognitions across the stages of change.

Threat did show a slight decreasing trend across the stages, but it was not significant. The high level of self-reported threat across the stages indicates that a strong threat of contracting HIV/AIDS and Hepatitis B is perceived regardless of whether or not a health care worker is recapping needles. According to Witte (1994) threat serves as a motivator for action. The action taken depends on the efficacy an individual perceives for the recommended action (in this case, not recapping needles). Witte (1992a) states that danger control responses take place when the perceived level of efficacy exceeds that of perceived threat. Similar to a study by Prochaska, Norcross, Fowler, Follick, and Abrams (1992) who found that self-efficacy increased significantly across the stages of change, the current study also showed this relationship. 
Perceived efficacy was reported to be significantly higher than threat in the maintenance stage and significantly lower than threat in the precontemplation stage. The significantly higher level of efficacy versus threat in the maintenance stage indicates that danger control responses should be occurring. This, in fact, was the case as those in the maintenance stage reported not recapping needles consistently. This was further bolstered because attitudes and intentions toward protecting oneself against HIV/AIDS and Hepatitis B increased significantly from the precontemplation to maintenance stage. Because perceived efficacy was also found to be significantly lower than perceived threat (and self reported non-recapping behavior was quite low) in the precontemplation stage, it might follow that fear control should have been initiated in the precontemplation stage (Witte, 1992a). As mentioned earlier, this was clearly not the case because self reported fear levels remained significantly high across the stages, so health care workers were not using fear control processes to manage their fear (or fear levels would have been reduced across the stages and fear control would have been higher in the initial stages).

The study findings tended to coincide with the EPPM tenet that danger control responses should be more prominent than fear control responses for those accepting a health risk message (i.e., performing desired behavior) (Witte, 1994), but the EPPM findings do not adequately explain the non-compliant behavior in early stages. Without evidence that the fear control process of denial was dominating in the lower stages, what might be an alternate explanation? One explanation may be that the concept of "reactance" was missing from the survey. This concept is also a fear control process and is defined as perceived manipulation and message derogation (Brehm, 1966). If certain respondents (especially those in precontemplation or contemplation) perceived that the likelihood of contracting HIV/AIDS or Hepatitis B was 
exaggerated, they may have also perceived some form of manipulation on the part of hospital management (this seems to coincide with the low safety climate ratings in early stages).

Reactance has been found to cause what is called a "boomerang" effect which is when people do the exact opposite of what is advocated (Witte, 1992b). Indeed, this seems to be what was reported as happening in the precontemplation stage (i.e., recapping needles). But, reactance was not measured in the study because of its greater relevance to experimental studies that examine the effects of fear appeal messages.

DeJoy (1996) states that the factors that influence "readiness to change" are not limited to person-focused variables (e.g., fear, threat, efficacy). Safety climate is a construct that taps the organizational factors that may impede compliant behavior in an occupational setting. It may be that negative safety climate perceptions are at least partially responsible for keeping health care workers from complying with non-recapping regulations. Findings related to safety climate were some of the most robust in this study. All of the safety climate factors examined (peer and supervisory feedback, management commitment to safety, personal protection equipment availability, and compliance barriers) significantly differed across the stages. Even the earliest work in safety climate indicated that strong positive relationships exist between safety climate and safety behaviors (Zohar, 1980). Since fear, threat, and fear control were stable across all stages, it is likely that safety climate perceptions play a significant role in the current framework. Future research should examine the relationship between safety climate and efficacy to determine if positive changes in safety climate perceptions in the initial stages lead to significant changes in efficacy later in stages of change. This would indicate a clear need for the addition of organizational or social factors to be considered in behavior change models because it has been 
found that even well-motivated and well-trained workers may not respond appropriately if doing so is not acknowledged or reinforced by peers, supervisors, and management (DeJoy, 1996). Implications for Health Risk Messages

The combined framework of the EPPM, Stages of Change, and Safety Climate concepts provides critical insight into improving the targeting of self-protective messages for health care workers regarding non-compliant needle recapping behavior. The EPPM provides personal characteristics that are important in motivating self-protective behavior, the Stages of Change emphasizes that self-protective behavior change is a dynamic process, and Safety Climate provides the descriptors of the environmental context. Therefore, messages for health care workers regarding recapping behavior should be developed within each stage of change and focus on personal variables (i.e., fear, threat, fear control, efficacy) and environmental context (i.e., safety climate). The finding that efficacy was significantly lower than threat in the precontemplation stage indicates that pre-contemplators have perceptions of inadequacy regarding their ability to consistently not recap needles and a lack of confidence that not recapping needles leads to a decreased likelihood of contracting HIV/AIDS or Hepatitis B. Prochaska (1994) states that denial is what holds pre-contemplators in the initial stage. Denial is what fear control supposedly tapped in this study. Yet, fear control was consistently low across all the stages. It may be that, similar to what Becker et al. (1990) found, those in the precontemplation stage do not view recapping as a risky behavior (risk was not directly assessed in the study). Despite the lack of denial in the precontemplation stage there still seems to be low motivation to change. Messages focused on pre-contemplators should avoid being made actionoriented (Maibach \& Cotton, 1995). Messages for pre-contemplators often focus on increasing 
knowledge about the severity of disease and personal risk (Maibach \& Cotton, 1995). But in the current study, health care workers consistently reported high threat (susceptibility + severity) and fear levels across the stages. It may be that greater emphasis should be placed on the personal responsibility for actions in light of the consequences to others in the workplace (Maibach \& Cotton, 1995). Study results indicated significantly lower safety climate scores for precontemplators, so health care workers also might benefit from knowing more about management's commitment to safety, since Prochaska (1994) states that pre-contemplators often seek scapegoats to justify their non-compliant behavior. Programs should also focus on promoting a clear message that non-compliant behavior will be handled in a consistent manner (Prochaska, 1994). Finally, pre-contemplators should have a clear indication of the benefits of compliant behavior so that they may begin to weigh them against the costs of compliant behavior (Maibach \& Cotton, 1995).

From the current study, it is not as clear how messages should be tailored for the three middle stages as it is for pre-contemplators and those in maintenance. Unfortunately, the sample size may have contributed to the "cloudiness" of findings in the three middle stages.

Contemplators are described as being eager to talk about their problems and seeking reassurance that they can overcome the problem at hand (Prochaska, 1994). It is at this stage that self-efficacy becomes an important emphasis (DeJoy, 1996). Self-efficacy can be enhanced through messages that promote the belief that health care workers have the ability to change. The data from the study did indicate a non-significant, but increasing trend from precontemplation to contemplation of efficacy perceptions indicating the need to promote efficacy. Since contemplators are thinking about change, messages can be more action oriented than those in 
precontemplation. DeJoy (1996) indicates that the cost-benefit relationship should be a focus in the contemplation stage. This would entail emphasizing the benefits of compliance versus deemphasizing the barriers to compliance as Maibach and Parrott (1994) report this to be most effective. It is in the contemplation stage that safety climate issues begin to be emphasized. Overcoming barriers, personal protection equipment availability, and managements' commitment to safety are important to highlight at this stage because they are considered as enabling factors for health care workers to behave properly and contemplators are on the verge of making a change.

The differences in perceptions among those in the preparation and contemplation stages are subtle, and Prochaska (1994) states that in his initial work these stages were actually combined. But, a difference between these two stages is that those in preparation have at least attempted the compliant behavior (they have not recapped some needles, although inconsistently). Those in the preparation stage are on the verge of beginning to consistently practice compliant behavior. This is the stage when behavioral intentions are translated to action (DeJoy, 1996). Indeed, the data indicated that both intentions to not recap needles to avoid contracting HIV/AIDS and Hepatitis B were significantly greater than those same intentions in the contemplation stage. Messages in the preparation stage should place a great emphasis on efficacy as skills to perform are crucial in maintaining the motivation to move into the action stage (Maibach \& Cotton, 1995). Safety climate factors such as management commitment to safety are important, but reinforcing feedback from supervisors and coworkers regarding compliant behavior and overcoming barriers to compliance are crucial aspects of moving an individual from preparation to action. Feedback from coworkers and supervisors regarding compliant behavior provides the reinforcement a 
health care worker needs to move to action. Perceptions regarding the barriers to compliance are also important to highlight in messages to preparers. Barriers such as "not being able to do my job to the best of my ability because of non-recapping" can be overcome by continuous demonstration that management supports the extra time the procedure might take and that job performance does not suffer. Prochaska (1994) states that it is during this stage that a focus on the "new self" should take place by emphasizing future actions rather than past behavior. Without the change to positive influences (or changes in the social network and cues) on compliant behavior, the preparer may well fall back into performing the non-compliant behavior.

Individuals in the action stage have been practicing compliant behavior for several months, but are still at a critical point in behavior change. Relapse into an earlier stage is still a distinct possibility. It is critical that messages at this stage focus on support and reinforcement of compliant behavior. Task and work environments should be portrayed as supportive of safe behavior under all conditions (DeJoy, 1996). In the current study, the data indicated that health care workers in the action stage had significantly greater perceptions of personal protective equipment availability and management commitment to safety than those in the preparation stage. This is an indication that health care workers place importance on these work environment variables and that they should be emphasized in health messages for those in the action stage.

Health care workers in the maintenance stage report having been performing non-recapping behavior consistently for more than 6 months. They have a significantly higher level of efficacy to perform the compliant behavior and belief that non-recapping of needles can help avoid contracting AIDS/HIV and Hepatitis B. It is in this stage that self-protective behavior, through its repetitive use, can become relatively automatic. This should help to maintain long term 
adherence to non-recapping standards. Like those in the action stage, long term maintenance requires an environment that supports safe behavior even under the most demanding or stressful conditions (DeJoy, 1996). Messages for those in the maintenance stage should not only focus on a supportive climate, but also on the refining of skills in order to avoid relapse and productive coping with set-backs to avoid severe relapse (Maibach \& Cotton, 1995).

It is clear from this study that health risk messages can be developed more effectively by incorporating safety climate and EPPM factors within the stages of change. This framework not only provides an alternative to targeting non-compliant versus compliant (by using a stage approach there are 3 groups of non-compliant and 2 compliant), but also incorporating the facets of environmental context (safety climate) along with person-related variables (EPPM constructs). Future research should focus on testing whether safety climate enhances health risk messages, whether messages across the stages of change are more effective than those that are strictly high threat/high efficacy, and whether a combination of the aforementioned is effective.

\section{Summary}

The purpose of this study was to examine the EPPM constructs across the stages of change to determine whether affect (e.g., fear and threat of HIV/AIDS or Hepatitis B) differed among those in the behavior change process of decreasing their needle recapping to become compliant with OSHA standards. Safety climate factors were also examined across the stages of change to determine whether environmental context played a role in the behavioral change process.

This cross-sectional study included self-reported demographics, needle stick information, and responses to a 71-item questionnaire that assessed perceptions related to the EPPM, stages of change, and safety climate from 161 health care workers employed at a small city hospital in the 
northeast United States.

Research regarding the EPPM has found that high levels of fear and threat lead to two responses: either danger control or fear control. In the current study, both fear and threat were consistently high across the stages of change, but did not significantly differ between initial and later stages. Fear control responses were found to be consistently low across the stages of change suggesting that findings were counterintuitive to the EPPM. Danger control responses (attitudes, intentions, and behavior) were found to significantly increase across the stages of change which is what one would expect according to the EPPM. On initial examination, because fear levels were high across the stages, it was thought that through the mediation of threat, fear may have been related to danger control responses. Surprisingly, even in high threat, high efficacy, or high-threat-high efficacy conditions, fear was unrelated to danger control responses. Fear control responses were significantly and negatively correlated with fear which is in direct contradiction to the EPPM that stipulates that fear is positively related to fear control. As discussed previously, this may have been because the construct of "reactance" was not included in fear control, but this too warrants further investigation.

Both stages of change research and EPPM research have found that efficacy expectations increase across the stages of change. This was also confirmed in the current study. Additionally, efficacy was significantly lower than threat in the precontemplation stage and significantly greater in the maintenance stage. These findings correspond to those in EPPM research that stipulate those with a significantly greater threat level than efficacy are more likely to be not be performing the recommended behavior than those with significantly greater efficacy levels versus threat. 
Safety climate research has consistently shown that strong relationships exist between perceptions of safety climate and safe workplace behaviors. The current study showed that safety climate variables differed significantly across the stages of change from precontemplation to maintenance. This indicates that safety climate is strongly related to the behavior change process of not recapping used needles.

Based on the results, the investigator stated that health risk messages can be more effectively developed using a combination framework of EPPM, Stages of Change, and Safety Climate constructs. It is clear that future experimental research is needed to further assess these findings. Studies might be designed that assess the effects of a fear appeal message or training program across the stages of change. Assessing fear, threat, efficacy, and safety climate perceptions both before and after an intervention across the stages of change would possibly provide more substantial evidence regarding the role of fear and safety climate in the behavioral change process. Other future research considerations include incorporating observations of needle use and disposal in assessing behavior change and developing an effective prediction model for nonrecapping behavior. 


\section{References}

Bandura, A. (1977). Self-efficacy: toward a unifying theory of behavior change. Psychological Review, 84(2), 191-215.

Beck, K. H. \& Frankel, A. (1981). A conceptualization of threat communications and protective health behavior. Social Psychology Quarterly, 44(3), 204-217.

Becker, M. H., Janz, N. K., Band, J., Bartley, J., Snyder, M. B., \& Gaynes, R. P. (1990). Noncompliance with universal precautions policy: Why do physicians and nurses recap needles? American Journal of Infection Control, 18(4), 232-239.

Bohrnstedt, G. W. \& Knoke, D. (1982). Statistics for Social Data Analysis. (p. 361). Itasca, IL: F. E. Peacock.

Brehm, J. W. (1966). A theory of reactance. New York: Academic Press.

Brown, R. L. \& Holmes, H. (1986). The use of a factor-analytic procedure for assessing the validity of an employee safety climate model. Accident Analysis \& Prevention, 18(6), 455-470.

Centers for Disease Control. (1988). Centers for Disease Control Update: universal precautions for prevention of transmission of human immunodeficiency virus, hepatitis $\mathrm{B}$, and other blood borne pathogens in health care settings. MMWR Morbidity Mortality Weekly Report, 37, 377-388.

Centers for Disease Control. (1991). Centers for Disease Control. Recommendations for preventing transmission of human immunodeficiency virus and hepatitis B virus to patients during exposure-prone evasive procedures. MMWR Morbidity Mortality Weekly Report, 40, $1-9$.

Centers for Disease Control and Prevention (1998). HIV/AIDS surveillance report, 10(1), 24.

Cohen, A. (1977). Factors in successful occupational safety programs. Journal of Safety Research, 9, 168-178.

Dedobbeleer, N. \& Beland, F. (1991). A Safety climate measure for construction sites. Journal of Safety Research, 22(2), 97-103.

DeJoy, D. M. (1985). Attributional processes and hazard control management in industry. Journal of Safety Research, 16, 61-71.

DeJoy, D. M. (1986). A behavioral-diagnostic model for self-protective behavior in the workplace. Professional Safety, 31, 26-30. 
DeJoy, D. M. (1996). Theoretical models of health behavior and workplace self-protective behavior. Journal of Safety Research, 27(2), 61-72.

DeJoy, D. M., Murphy, L. R., \& Gershon, R. M. M. (1995). Safety climate in health care settings. In A. C. Bittner \& P. C. Champney (Eds.), Advances in Industrial Ergonomics and Safety VII. (pp. 923-929). New York, NY: Taylor \& Francis.

DiClemente, C. C., Prochaska, J. O., Fairhurst, S. K., Velicer, W. F., Velasquez, M. M., \& Rossi, J. S. (1991). The process of smoking cessation: An analysis of precontemplation, contemplation, and preparation stages of change. Journal of Consulting and Clinical Psychology, $\underline{59}(2), 295-304$.

Dijkstra, A., De Vries, H., \& Bakker, M. (1996). Pros and cons of quitting, self-efficacy, and the stages of change in smoking cessation. Journal of Consulting and Clinical Psychology, 64(4), 758-763.

Dooley, D. (1990). Social Research Methods. (p.136). Trenton, NJ: Prentice-Hall.

DuPont, E. H. (1991). Fear of AIDS among intravenous drug users in London and New York. The International Journal of the Addictions, 26(2), 203-212.

Gershon, R. R. M., Karkashian, C., \& Felknor, S. (1994). Universal Precautions: An Update. Heart \& Lung, 23, 352-358.

Gershon, R. R. M., Vlahov, D., Felknor, S. A., Vesley, D., Johnson, P. C., Delclos, G. L., \& Murphy, L. R. (1995). Compliance with universal precautions among health care workers at three regional hospitals. American Journal of Infection Control, 23 (4), 225.236.

Grady, M. M., Shortridge, L. A., Davis, L. S., Klinger, C. S. (1993). Occupational exposure to bloodborne diseases and universal precautions: Measurement of health care workers' self reported attitudes. AAOHN Journal, 41(11), 533-540.

Grimley, D. M., Riley, G. E., Bellis, J. M., \& Prochaska, J.O. (1993). Assessing the stages of change and decision-making for contraceptive use for the prevention of pregnancy, sexually transmitted diseases, and acquired immunodeficiency syndrome. Health Education Quarterly, $\underline{20}(4), 455-470$.

Henry, K., Campbell, S., \& Maki, M. (1992). A comparison of observed and self-reported compliance with universal precautions among emergency department personnel at a Minnesota public teaching hospital: Implications for assessing infection control programs. Annals of Emergency Medicine, 21(8), 940-946. 
Henry, K., Campbell, S., Collier, P., \& Williams, C. O. (1994). Compliance with universal precautions and needle handling disposal practices among emergency department staff at two community hospitals. American Journal of Infection Control, 22(3), 129-137.

Hersey, J. C. \& Martin, L. S. (1994). Use of infection control guidelines by workers in healthcare facilities to prevent occupational transmission of HBV and HIV: Results from a national survey. Infection Control and Hospital Epidemiology, 15, 243-252.

Hoffman, D. A. \& Stetzer, A. (1996). A cross-level investigation of factors influencing unsafe behaviors and accidents. Personnel Psychology, 49(2), 307-339.

Hovland, C., Janis, I. \& Kelly, H. (1953). Communication and Persuasion, New Haven, CT: Yale University Press.

Howell, M. (1987). Statistical Methods for Psychology (pp.206-207), Boston, MA: PWSKent Publishing Co.

Janis, I. L. (1967). Effects of fear arousal on attitude change: Recent developments in theory and experimental research. In L. Berkowitz (Ed.), Advances in experimental social psychology (Vol. 3, pp. 166-225). New York, NY: Academic Press.

Janis, I. L. \& Mann, L. (1977). Decision-making: A psychological analysis of conflict, choice, and commitment. New York, NY: Free Press.

Leventhal, H. (1970). Findings and theory in the study of fear communications. In L. Berkowitz (Ed.), Advances in experimental social psychology (Vol. 5, pp. 119-186). New York, NY: Academic Press.

Leventhal, H., Singer, R., \& Jones, S. (1965). Effects of fear and specificity of recommendation upon attitudes and behavior. Journal of Personality and Social Psychology, $\underline{2}(1), 20-29$.

Leventhal, H., Jones, S., \& Trembly, G. (1966). Sex differences in attitude and behavior change under conditions of fear and specific instructions. Journal of Personality and Social Psychology, 2(4), 387-399.

Leventhal, H., Watts, J. C., \& Pagano, F. (1967). Affects of fear and instructions on how to cope with danger. Journal of Personality and Social Psychology, 6(3), 313-321.

Mahoney, F., Stewart, K., Hu, H., Coleman, P., \& Alter, M. (1997). Progress toward the elimination of hepatitis B virus transmission among health care workers in the United States. Archives of Internal Medicine, 157(22), 2601-2605. 
Maibach, E. W. \& Cotton, D. (1995). A staged social cognitive approach to message design. In E. Maibach \& R. L. Parrott (Eds.), Designing Health Messages (pp. 41-64). Thousand Oaks, CA: Sage.

Marcus, B. H., Rakowski, W., \& Rossi, J. S. (1992). Assessing motivational readiness and decision making for exercise. Health Psychology, 11(4), 257-261.

Marcus, B. H., Eaton, C. A., Rossi, J. S., \& Harlow, L. L. (1994). Self-efficacy, decisionmaking, and stages of change: An integrative model of physical exercise. Journal of Applied Social Psychology, 24(6), 489-508.

Marcus, R. (1988). The CDC cooperative needlestick surveillance group. Surveillance of health care workers exposed to blood from patients infected with the human immunodeficiency virus. New England Journal of Medicine, 319, 1118-1123.

McConnaughy, E. A., Prochaska, J. O., \& Velicer, W. F. (1983). Stages of change in psychotherapy: Measurement and sample profiles. Psychotherapy: theory, research and practice, $\underline{20}(3), 368-375$.

McGuire, W. J. (1969). The nature of attitudes and attitude change. In G. Lindzey \& E. Aronson (Eds.), The handbook of social psychology (Vol. 3, pp. 136-314). Reading, MA: Addison-Wesley.

Mewborn, C. R. \& Rogers, R. W. (1979). Effects of threatening and reassuring components of fear appeals on physiological and verbal measures of emotion and attitudes. Journal of Experimental and Social Psychology, 15, 242-253.

Michalsen, A., Delclos, G. L., Felknor, S. A., Davidson, A. L., Johnson, P. C., Vesley, D., Murphy, L. R., Kelen, G. D., \& Gershon, R. R. M. (1997). Compliance with universal precautions among physicians. Journal of Occupational and Environmental Medicine, 39(2), $130-137$.

Moore, D. S. \& McCabe, G. P. (1989). Introduction to the Practice of Statistics (pp.741742). New York, NY: W.H. Freeman.

Porter, L. W. \& Lawler, E. E. III (1965). Properties of organizational structure in relation to job attitudes and job behavior. Psychological Bulletin, 64, 23-51.

Prochaska, J. O. (1991). Assessing how people change. Cancer, 67, 805-807.

Prochaska, J. O. (1994). Strong and weak principles for progressing from precontemplation to action on the basis of twelve problem behaviors. Health Psychology, 13(1), 47-51. 
Prochaska, J. O., Norcross, J. C., Fowler, J. L., Follick, M. J., \& Abrams, D. B. (1992). Attendance and outcome in a work site weight control program: processes and stages of change as process and predictor variables. Addictive Behaviors, 17, 35-45.

Prochaska, J. O., Norcross, J. C., \& DiClemente, C. C. (1994c). Changing For Good (p. 15) New York, NY: Avon.

Prochaska, J. O., Redding, C. A., Harlow, L. L., Rossi, J. S., \& Velicer, W. F. (1994a). The transtheoretical model of change and HIV prevention: A review. Health Education Quarterly, 21(4), 471-486.

Prochaska, J. O., Velicer, W. F., Rossi, J. S., Goldstein, M. G., Marcus, B. H., Rakowski, W., Fiore, C., Harlow, L. L., Redding, C. A., Rosenbloom, D., \& Rossi, S. R. (1994b). Stages of change and decisional balance for 12 Problem behaviors. Health Psychology, 13(1), 39-46.

Rakowski, W., Fulton, J. P., \& Feldman, J. P. (1993). Women's Decision Making About Mammography: A replication of the relationship between stages of adoption and decisional balance. Health Psychology, 12(3), 209-214.

Ramirez, A. \& Lasater, T. L. (1976). Attitudinal and behavioral reactions to fear-arousing communications. Psychological Reports, 38, 811-818.

Ray, M. \& Wilkie, W. (1970). Fear: the potential of an appeal neglected by marketing? Journal of Marketing, 34, 54-62.

Rogers, R. W. (1983). Cognitive and physiological processes in fear appeals and attitude change: A revised theory of protection motivation. In J. Cacioppo \& R. Petty (Eds.), $\underline{\text { Social }}$ psychophysiology (pp.153-176). New York, NY: Guilford.

SAS (1990). SAS/STAT User's Guide Volume 2, GLM-VARCOMP. SAS Institute, Inc. Cary, NC.

SAS (1996). SAS Institute, Inc. Cary, NC.

Schneider, B. (1973). The perceptions of organizational climate: the customer's view. Journal of Applied Psychology, 57, 248-256.

Snow, M. G., Prochaska, J. O., \& Rossi, J. S. (1992). Stages of change for smoking cessation among former problem drinkers: A cross-sectional analysis. Journal of Substance Abuse, 4, 107116.

Sternthal, B. \& Craig, C. S. (1974). Fear appeals: revisited and revised. Journal of Consumer Research, 1, 22-34. 
Sutton, S. R. (1982). Fear-arousing communications: A critical examination of theory and research. In S. R. Sutton \& J. R. Eiser (Eds.), Social psychology and behavioral medicine (pp. 303-337). London: Wiley.

Sutton, S. R. \& Eiser, R. E. (1984). The effect of fear-arousing communications on cigarette smoking: an expectancy-value approach. Journal of Behavioral Medicine, 7(1), 13-33.

Velicer, W. F., DiClemente, C. C., Prochaska, J. O., \& Brandenburg, N. (1985). A decisional balance measure for assessing and predicting smoking status. Journal of Personality and Social Psychology, 48, 1279-1289.

Witte, K. (1992a). Putting the fear back into fear appeals: The extended parallel process model. Communication Monographs, 59, 329-349.

Witte, K. (1992b). The role of threat and efficacy in AIDS prevention. International Quarterly of Community Health Education, 12(3), 225-249.

Witte, K. (1994). Fear control and danger control: A test of the extended parallel process model (EPPM). Communication Monographs, 61, 113-134.

Witte, K. (1997). Preventing teen pregnancy through persuasive communications: realities, myths, and the hard-fact truths. Journal of Community Health, 22(2), 137-154.

Witte, K. (1998). Fear as motivator, fear as inhibitor: Using the extended parallel process model to explain fear appeal successes and failures. In P. A. Andersen \& L. K. Guerrero (Eds.), Handbook of Communication and Emotion: Research, Theory, Applications, and Contexts (pp. 423-450). New York, NY: Academic Press.

Witte, K., Peterson, T. R., Vallabhan, S., Stephenson, M. T., Plugge, C. D., Givens, V. K., Todd, J. D., Becktold, M. G., Hyde, M. K., \& Jarrett, R. (1993). Preventing tractor-related injuries and deaths in rural populations: Using a persuasive health message framework in formative evaluation research. International Quarterly of Community Health Education, 13(3), 219-251.

Witte, K. \& Allen, M. (1996). When do scare tactics work? A meta-analysis of fear appeals. Paper presented at the annual meeting of the Speech Communication Association, San Diego, CA.

Witte, K., Cameron, K. A., McKeon, J. K. \& Berkowitz, J. M. (1996). Predicting risk behaviors: Development and validation of a diagnostic scale. Journal of Health Communication, $1,317-341$. 
Wong, E. S., Stotka, J. L., Chinchilli, V. M., Williams, D. S., Stuart, C. G., \& Markowitz, S. M. (1991). Are universal precautions effective in reducing the number of occupational exposures among health care workers? A prospective study of physicians on a medical service. Journal of the American Medical Association, 265(9), 1123-1128.

Zohar, D. (1980). Safety climate in industrial organizations: Theoretical and applied implications. Journal of Applied Psychology, 65(1): 96-102. 
Appendices 


\section{Appendix A}

Institutional Review Board Material

$-75-$ 
DATE: May 20, 1998

NOTICE OF APPROVAL FOR PROTOCOL H.S. \#14154

This research will be monitored for re-approval annually. This protocol was first approved on May 20, 1998.

\section{TO: Brian Day}

Project Title: Personal Perceptions Regarding Bloodborne diseases in Health Care Workers

\section{SPONSORING AGENCY: N/A}

The Institutional Review Board for the Protection of Human Research subjects (IRB) has approved the project described above. Approval was based on the descriptive material and procedures you submitted for review. Should any changes in your protocol/consent form be necessary, prior approval must be obtained from the IRB.

According to the Code of Federal Regulations, Section 312.32, investigators are required to notify the FDA and the study sponsor of any adverse experience associated with the use of an investigational drug that is serious and unexpected. A serious adverse experience is considered any event that is fatal or life-threatening, is permanently disabling, requires inpatient hospitalization, or is a congenital anomaly, cancer, or overdose. An unexpected adverse experience is an event that is not identified in nature, severity, or frequency in the current investigator brochure. Any experience reportable to FDA and the sponsor must also be reported immediately to the IRB.

A consent form*__ is $\mathrm{X}$ is not required of each subject.

An assent form_ is $X_{-}$is not required of each subject.

A recruitment ad has has not $X$ been approved.

NOTE: Consent form has been waived. 
Page 2-

Day

HS \#14154

May 20, 1998

* Only copies of the consent and/or assent form with the IRB's approval stamp may be used with human subject research. It is the responsibility of the investigator to submit a revised consent form for the IRB's approval should funding be obtained. This stamped consent form must then be used for subjects enrolled. A copy of each subject's signed Consent/Assent Form must be retained by the investigator and accessible to- federal regulatory authorities for at least three years after the study is completed.

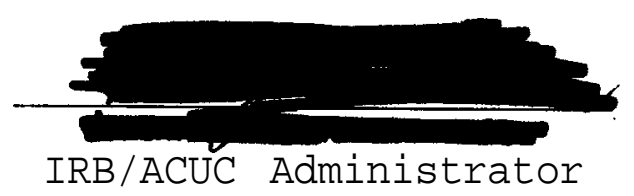

MJT/baw 


\section{Institutional Review Board Protocol Statement}

1. Tite of study: Persinal Perceptions Regarding Elocdborne Discases in Health Cave Workers

2. Investigators list all investigators, principal investigator first; attach additional sheets if necessary:

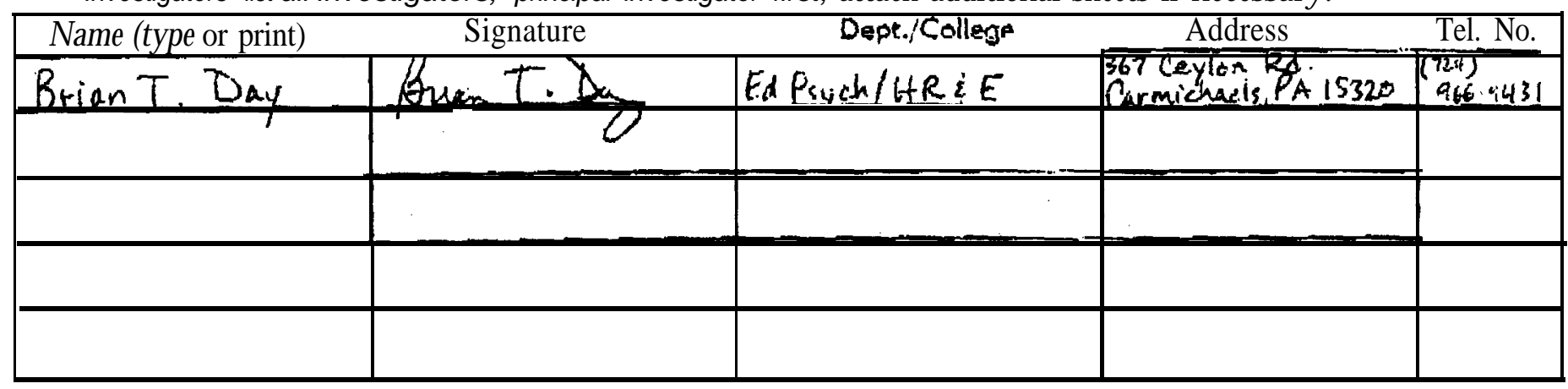

3. Review category requested: $\boldsymbol{X}$ quorum

Expedited

4 Estimated period of human subject involvement: Starting date: Maxi8 Ending date; June. 1998

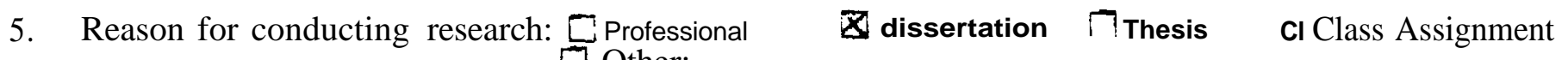
$\square$ Other: 4pectif

6. Investigators at institutions other than $W V U$ or units of the Health Sciences Center: Institutional Affiliation $\quad$ Name Title Role in Study

7. Persons other than the investigators who will have contact with subjects:

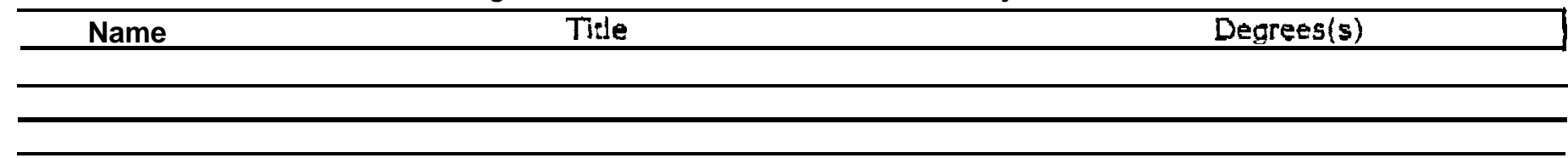

8. Persons other than the investigators who will obtain informed consent:
Name
Title
Degrees(s)

9 Persons other than the investigators who will have contact with data:

Name Title Degree(s)

10. Locetion for interartion with subjects (provide name of institution, address, and brief description):

\section{पoe Bed facility - teaching hoepial}


05,1398 FED 1\$:25 5.2工 $304283 \quad 7435$

i1. Indicate w'th $a<$ whict of the following populasone will be included im the research:

\section{Patients}

Children (inder (8)

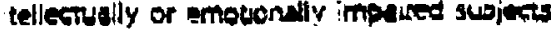

Jderiy subjects (over 63)

Pregnant subjects or tebuset

Prisuners. porolews. incerserated subjeqs

Miliserata subjeces

Subjest whose pritrary ianguege is not Engilss

Saudente or traincess

Enployeses of metitutions ssoxiand wien the study

Employest or subacinates of investigaror:
12. Indleate by a $\alpha$ if any of the following tems are invo!ved:

Oata sellested trom daie banks, archives. Medical recorts

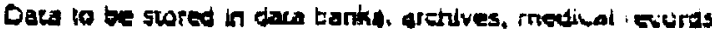

Filming, videsuping, of volew-resending of subjects

Qumivimuires

lonizing radiation, ether alagnastic or thepopeztic

Puthological or diegnostic wasue or flutet

Pasental issue

Petal vasue

Aeproved dnag is device in "mon-FDA-approved" applleation

Precestede)

Devepiten of entojects

\section{Mathod of obtuining informed consent:}

Wwituen consent form (includs copy in section C)

- requesting waiver or alteration of consent process (explain in Section C)

14. Method of obtalning assent from ehildren (under age 18) or incompetent subjects: writien assent form (inelude a copy in section C)

- no assent. undes age 7 or severdy impaired (explain in Section C)

- requesting waive: ur alteiacion of assent pruxess (explain in sectren e)

15. Wil investigational dugs of devices be used?
- yes 1 nn
If yes: IND*
or IDE.
Manufacturer:

\section{Souree of hunding support (if applieable):}

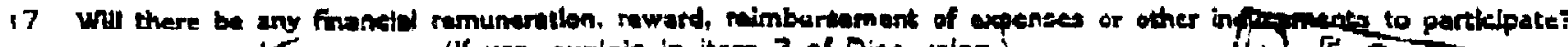
- yes (fine you, explain in item 3 of Discusslon.)

18. Will there any potential added cost to subjects?
yes rno
(if yes, explain in Item 4 of Dlecussion.)

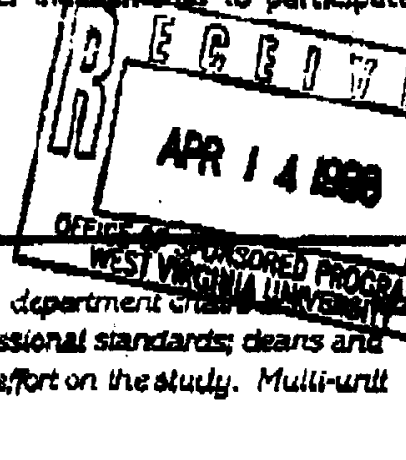

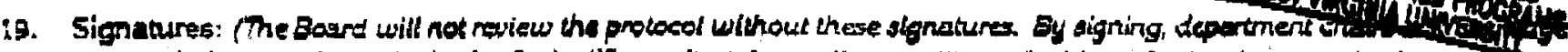

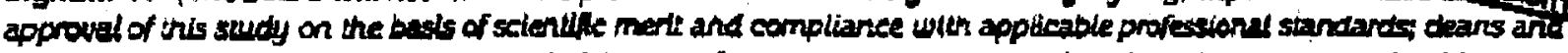

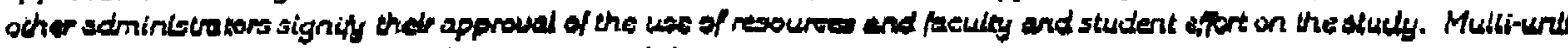
prococols require the dionatures of exch chair and dean.)

Nane (type or pint) Tibe Sijenature Date

Dean

Dean

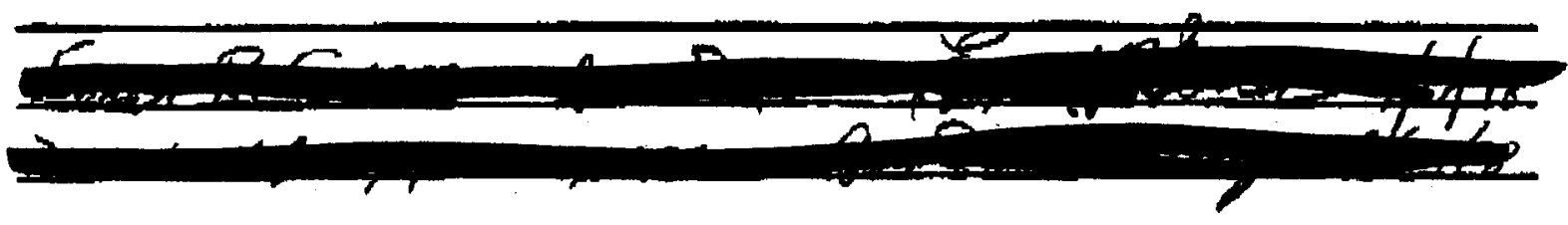

Dnpt. Chalr

Hospital Admint

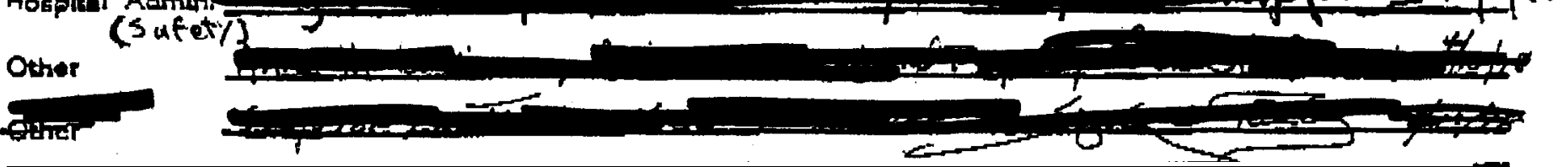

Fall 1992 


\section{B. Abstract}

\section{Doctoral Dissertation}

Personal Perceptions Regarding Bloodborne Diseases in Health Care Workers

Universal precautions were mandated for the purpose of decreasing the risk of bloodborne pathogen transmission of diseases, namely human immunodeficiency virus and hepatitis B infections. One of the stipulations of universal precautions is that used needles should not be recapped and should be disposed of in an appropriate sharps container. The rate of needle stick injuries among nurses remains at a high level despite the passage of the Occupational Safety and Health Administration (OSHA) regulations regarding universal precautions in March of 1992. The role fear plays in decisions regarding health related behaviors such as intravenous drug use has been critically examined, but fear related to occupationally related behavior (e.g., needle recapping and disposal by health care workers) has received little attention. With the severe threat of bloodborne diseases such as AIDS and Hepatitis B, it is important to determine what role fear plays in enhancing or deterring universal or standard precautions (specifically, not recapping used needles) compliance behavior.

The purpose of this study is to determine the differences in fear, threat, and efficacy levels across the five stages of change for health care workers who routinely handle needles and/or other sharps. The procedure used to assess these perceptions is a self-administered mail questionnaire. 


\section{Discussion}

1. Purposes and Procedures

Objectives:

The purpose of this study is to determine the differences in fear, threat, and efficacy levels across the five stages of change for health care.workers who routinely handle needles and/or other sharps using a self-administered mail questionnaire.

Procedures:

1. Assuming a 40 to $50 \%$ response rate, draw a random sample of 500 eligible participants from a roster provided by the

2. Mail the questionnaire to eligible participants through hospital mail system.

3. To boost participation rate, attend worker shift meetings and explain purpose and importance of study.

4. Analyze data

2. Subjects

The proposed number of subjects is 155 . The subjects will be health care workers at who routinely handle needles and/or other sharps during the course of their work. The subjects will be randomly selected using an employee roster provided by Safety Director.

3. Payments to Subjects $\mathrm{N} / \mathrm{A}$

4. Costs to Subjects $\mathrm{N} / \mathrm{A}$

5. Benefits

There are no benefits to subjects for participating in the study.

6. Risks and Discomforts

There are no risks and discomforts for the subjects related to this research project.

7. Radiation

$\mathrm{N} / \mathrm{A}$

8. Debriefing

Since the survey is totally anonymous, subjects will not be debriefed.

9. Intervention

$\mathrm{N} / \mathrm{A}$

10. Confidentiality

Anonymity is guaranteed because none of the return data forms will contain subject identifiers. Audio or video tapes of subjects will not be used in this study. 
C. Consent Form - none required 
11. Principal Investigator

Brian Thomas Day

B.A. Sociology, 1982

M.A. Social Research, 1988

Health Statistician, National Institute for Occupational Safety and Health.

12. Other Investigators

$\mathrm{N} / \mathrm{A}$

13. Other Participants

Dr. Anne Nardi is the chair of my doctoral committee. She will serve as a supervisor and consultant for this project. 
To: Health Care Worker

MAY 201998 APRROVED

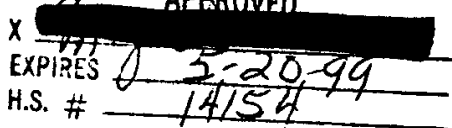

You have been randomly selected to participate in a research project that is sponsored by Department of Safety. The purpose of this study will be to examine the attitudes, beliefs, and behaviors regarding health care workers who routinely handle needles and sharps. Your participation will include filling out a set of questionnaires that will take approximately 20 minutes to complete.

If you decide to participate, it is most important that you answer the questions honestly. By doing so, the researcher can be assured that the responses best represent the participants. Your participation in this project is strictly voluntary and the information gathered will be kept

\section{COMPLETELY ANONYMOUS.}

The benefits of participating in this project include assisting the researcher in examining a problem which eventually may lead to new developments in how health care workers are trained regarding the proper handling and disposal of needles and sharps.

If you are interested in participating in this important research, please complete and return the enclosed questionnaires. Use the self addressed envelope and place it mail. If you have any questions regarding this research project, you can contact

285-62 11.

Please consider your possible participation seriously as it may make a difference in how bloodborne pathogens training is developed in the future.

Sincerely,
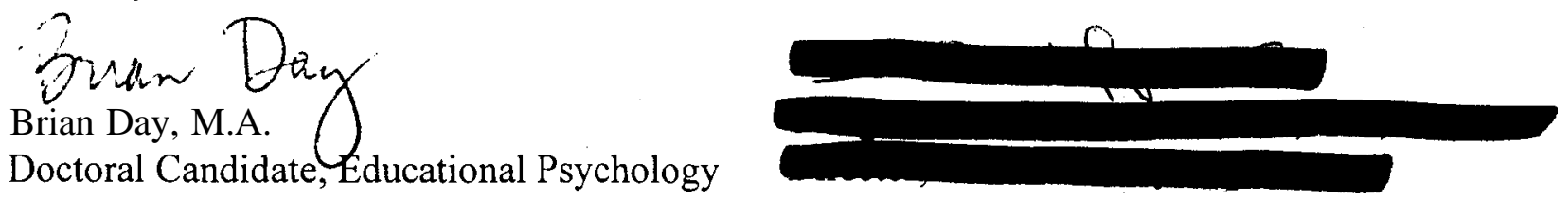

$-84-$ 
This is to inform you that Brian Day works at NIOSII and we have parlicipated in one of his research proiccts concerning Respiratory Prolection againgt Tuberculosis(1D).

I would greatly appreciale your assistance to encourage your staft to complete the survey. The results of the study may help us to deal betler with the needlestiok incidents that oceur herc at

\section{MFMORANDUM}

To: Supervisnrs, directors, and manwgers of health care workers who routinely handle neodles and sharps

From: Brian Day, Doctoral casdidate in Educational Psychology

In the next two weeks a random and anonymous sample of health care workcrs will reccive a questionnaire regurding their attitudes, beliefs, and behaviots regarding the use of ncedlos and sharps and their disposal. 'l'he study scsults will be used to develop more effective techniques or sharing crucial safety informalion with bealth care workers all over the cuuntry. I would ask that you please mention the importance of your fellow Workers' participation in this sludy. Il is also crucial that participants know that the information they share through the questionnuires in this study will remain complectly anonymous and that their participation will is now way arfect their job status. Stating this to all possible paticipants will help to elicit the most honest responses. I would greatly appreciale your ctrorts in assisting to make this study a success. Thank you.

WLST VIRGIHIA LWIVERSITY institution Review Board for ths Pro: Hon of Humon Reacareil Sibingts

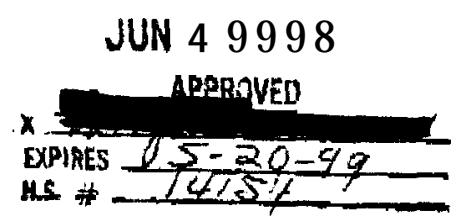




\section{Participant Information}

1. Are you a:

\begin{tabular}{llll} 
phlebotomist & $\circ$ & medical technician & $\circ$ \\
nurse & $\circ$ & clinical associate & $\circ$ \\
lab technician & $\circ$ & support associate & $\circ$ \\
surgical technician & $\circ$ & other \\
& $\quad \quad$ specify: & $\circ$ \\
\hline
\end{tabular}

2. Do you handle needles or other sharps as part of your job? Yes $\circ$ No $\circ$ (IF NO, discontinue filling out questionnaire and return - Thank you)

3. How many years have you worked with needles and sharps?

4. Gender: Male $\bigcirc$ Female $\circ$

5. Age:

6. On average, how many tasks involving needles or sharps do you perform in a week?

7. Did you receive universal precautions or standard precautions training in the past Yes $\circ$ No $\circ$ (NO, go to \#8)

7a. How many hours of training? (hours)

7b. IF YES: Did the training included policies regarding the handling and disposal of used needles? Yes $\circ$ No $\circ$

8. Have you EVER experienced a needle stick of any kind?

IF YES: Was this your first needle stick?

Was the needle contaminated with blood?

Did this incident occur within the past year?

year?

9. Do you know someone who has experienced a needle stick?

IF YES: (Answer regarding most recent needle stick)

$\begin{array}{ll}\text { Is this the only person you know } & \\ \text { who has had a needle stick? } & \text { Yes } \circ \text { No } \circ \\ \text { Was the needle contaminated with blood? } & \text { Yes } \circ \text { No } \circ \\ \text { Did this incident occur within the past year? } & \text { Yes } \circ \text { No } \circ\end{array}$

All Responses will be kept strictly anonymous. 


\section{Participants Safety Climate Questionnaire}

PLEASE ANSWER THE FOLLOWING QUESTIONS ABOUT YOUR WORKPLACE BY CIRCLING YOUR RESPONSE. Read the choices below carefully.

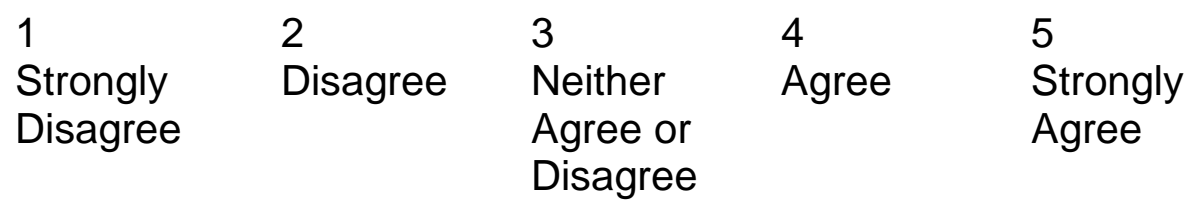

1. The protection of workers from occupational exposures to $\mathrm{HIV} / \mathrm{Hepatitis} \mathrm{B}$ is a high priority with management where I work.

$\begin{array}{lllll}1 & 2 & 3 & 4 & 5\end{array}$

2. Employees are told when they do not follow nonrecapping standards.

$\begin{array}{lllll}1 & 2 & 3 & 4 & 5\end{array}$

3. Sharps containers are readily available in my facility.

$\begin{array}{lllll}1 & 2 & 3 & 4 & 5\end{array}$

4. Employees in my work group remind each other about not recapping needles.

5. In this hospital, all reasonable steps are taken to minimize hazardous job tasks and procedures.

$\begin{array}{lllll}1 & 2 & 3 & 4 & 5\end{array}$

6. All of the necessary equipment and devices to help me avoid contact with HIV/Hepatitis B are readily available. $\begin{array}{llllll}1 & 2 & 3 & 4 & 5\end{array}$

7. In my organization, there are no significant compromises or shortcuts taken by employees when worker protection from infectious diseases is at stake.

8. I sometimes recap needles because "patients' needs come first."

$\begin{array}{lllll}1 & 2 & 3 & 4 & 5\end{array}$

9. I am knowledgeable about why I should not recap used needles.

10. Where I work, employees, supervisors, and managers work together to insure the safest possible working conditions.

\section{All Responses will be kept strictly anonymous.}




$\begin{array}{lllll}1 & 2 & 3 & 4 & 5 \\ \text { Strongly } & \text { Disagree } & \begin{array}{l}\text { Neither } \\ \text { Agree or } \\ \text { Disagree }\end{array} & \text { Agree } & \text { Strongly } \\ & & \text { Disagree } & & \text { Agree }\end{array}$

11. At this hospital, medical waste containers and bags are readily available.

12. My job duties often interfere with my being able to not recap needles.

13. Policies regarding not recapping used needles are posted.

14. This hospital provides me with all the necessary equipment and devices in order for me to protect myself from HIV/Hepatitis B exposures.

15. No t recapping needles keeps me from doing my job to the best of my abilities.

16. New employees quickly learn that they are expected to not recap needles.

$\begin{array}{lllll}1 & 2 & 3 & 4 & 5\end{array}$

17. I do not have enough information in order to correctly comply with non-recapping standards in my work.

18. On my job, I am allowed to decide how to go about completing my assigned tasks.

19. Conflicts are brought out into the open in my work group.

20. I sometimes recap needles because patients' needs come before employee safety. 


\section{PLEASE READ THE FIVE STATEMENTS BELOW AND}

CIRCLE THE ONE WHICH DESCRIBES YOU BEST.

These statements refer only to needles and sharps that are not to be recapped according to universal standards (some surgical and anesthesia needles should be recapped)

Read all five of the choices carefully before making your decision. You may choose only one statement.

1. I do not plan on stopping my occasional or frequent recapping of needles.

2. I recap needles, but I am seriously thinking about stopping that in the next 6 months.

3. I have sometimes stopped recapping needles in the past year and now I am seriously planning to stop my recapping behavior altogether in the next month.

4. I do not recap needles now and have not recapped ANY for 0 to 6 months.

5. I do not recap needles now and have not recapped ANY for more than 6 months.

All Responses will be kept strictly anonymous. 


\section{Health Care Worker Questionnaire}

PLEASE INDICATE THE EXTENT OF YOUR AGREEMENT WITH THE FOLLOWING BY CIRCLING YOUR RESPONSE. READ THE QUESTIONS BELOW CAREFULLY.

\begin{tabular}{|c|c|c|c|c|}
\hline $\begin{array}{l}1 \\
\text { Strongly } \\
\text { Disagree }\end{array}$ & $\begin{array}{l}2 \\
\text { Disagree }\end{array}$ & $\begin{array}{l}3 \\
\text { Neither } \\
\text { Agree or } \\
\text { Disaaree }\end{array}$ & $\begin{array}{l}4 \\
\text { Agree }\end{array}$ & $\begin{array}{l}5 \\
\text { Strongly } \\
\text { Agree }\end{array}$ \\
\hline
\end{tabular}

1. I believe that HIV/AIDS is a severe condition.

2. I am at risk for getting HIV/AIDS.

3. I intend to recap needles to help prevent myself from contracting HIV/AIDS.

4. HIV/AIDS frightens me.

5. I am able to not recap used needles and sharps to help prevent myself from contracting HIV/AIDS.

6. Not recapping used needles and sharps is an effective HIV/AIDS prevention measure.

7. I believe that Hepatitis $B$ is a serious condition.

8. It is possible that I will contract HIV/AIDS.

9. I often recap needles when performing procedures that require their use.

10. I plan to recap needles to help prevent myself from contracting HIV/AIDS.

11. When I hear about needle stick injuries leading to Hepatitis B infection, I spend additional time thinking about them. $\begin{array}{lllll}1 & 2 & 3 & 4 & 5\end{array}$

$\begin{array}{lllll}1 & 2 & 3 & 4 & 5\end{array}$

$\begin{array}{lllll}1 & 2 & 3 & 4 & 5\end{array}$

$\begin{array}{lllll}1 & 2 & 3 & 4 & 5\end{array}$

$\begin{array}{lllll}1 & 2 & 3 & 4 & 5\end{array}$

$\begin{array}{lllll}1 & 2 & 3 & 4 & 5\end{array}$

$\begin{array}{lllll}1 & 2 & 3 & 4 & 5\end{array}$

$\begin{array}{lllll}1 & 2 & 3 & 4 & 5\end{array}$

$\begin{array}{lllll}1 & 2 & 3 & 4 & 5\end{array}$

$\begin{array}{lllll}1 & 2 & 3 & 4 & 5\end{array}$

$\begin{array}{lllll}1 & 2 & 3 & 4 & 5\end{array}$

\section{All Responses will be kept strictly anonymous.}




\begin{tabular}{|c|c|c|c|c|}
\hline $\begin{array}{l}1 \\
\text { Strongly } \\
\text { Disagree }\end{array}$ & $\begin{array}{l}2 \\
\text { Disagree }\end{array}$ & $\begin{array}{l}3 \\
\text { Neither } \\
\text { Agree or } \\
\text { Disagree }\end{array}$ & $\begin{array}{l}4 \\
\text { Agree }\end{array}$ & $\begin{array}{l}5 \\
\text { Strongly } \\
\text { Agree }\end{array}$ \\
\hline
\end{tabular}

12. Not recapping used needles and sharps minimizes the chance of contracting Hepatitis B.

13. Hepatitis B scares me.

14. HIV/AIDS makes me feel anxious.

15. Not recapping used needles and sharps to help prevent contract Hepatitis B is easy to do.

$\begin{array}{lllll}1 & 2 & 3 & 4 & 5\end{array}$

$\begin{array}{lllll}1 & 2 & 3 & 4 & 5\end{array}$

$\begin{array}{lllll}1 & 2 & 3 & 4 & 5\end{array}$

16. I intend to recap needles to help prevent

myself from contracting Hepatitis B.

$\begin{array}{lllll}1 & 2 & 3 & 4 & 5\end{array}$

17. Not recapping used needles and sharps is an effective Hepatitis B prevention measure.

$\begin{array}{lllll}1 & 2 & 3 & 4 & 5\end{array}$

18. I believe that HIV/AIDS is a significant problem.

$\begin{array}{lllll}1 & 2 & 3 & 4 & 5\end{array}$

19. It is likely that I will contract Hepatitis B.

$\begin{array}{lllll}1 & 2 & 3 & 4 & 5\end{array}$

20. News of needle stick injuries leading to HIV/AIDS infection makes me stop and think about my own personal safety.

$\begin{array}{lllll}1 & 2 & 3 & 4 & 5\end{array}$

21. Hepatitis B frightens me.

$\begin{array}{lllll}1 & 2 & 3 & 4 & 5\end{array}$

22. Not recapping used needles and sharps to help prevent contracting HIV/AIDS is inconvenient.

$\begin{array}{lllll}1 & 2 & 3 & 4 & 5\end{array}$

23. I plan to recap needles to help prevent myself from contracting Hepatitis B.

$\begin{array}{lllll}1 & 2 & 3 & 4 & 5\end{array}$

24. Not recapping used needles and sharps helps to prevent contracting Hepatitis B.

$\begin{array}{lllll}1 & 2 & 3 & 4 & 5\end{array}$

25. When I hear about needle stick injuries leading to HIV/AIDS infection, it makes me concentrate on using universal or standard precautions.

\section{All Responses will be kept strictly anonymous.}




$\begin{array}{lllll}1 & 2 & 3 & 4 & 5 \\ \text { Strongly } & \text { Disagree } & \begin{array}{l}\text { Neither } \\ \text { Agree or } \\ \text { Disagree }\end{array} & \text { Agree } & \begin{array}{l}\text { Strongly } \\ \text { Disagree }\end{array} \\ & & & \text { Agree }\end{array}$

26. I believe Hepatitis $B$ is a severe condition.

27. It is likely that I will contract HIV/AIDS.

28. Hepatitis B makes me feel anxious.

29. I am able to not recap used needles or sharps to help prevent myself from contracting Hepatitis B. $\begin{array}{llllll}1 & 2 & 3 & 4 & 5\end{array}$

30. Not recapping used needles and sharps to help prevent contracting Hepatitis $B$ is inconvenient.

31. I believe that HIV/AIDS is a serious condition.

32. I believe that Hepatitis B is a significant problem.

33. Not recapping used needles and sharps minimizes the chance of contracting HIV/AIDS.

34. HIV/AIDS scares me.

35. It is possible that I will contract Hepatitis B.

36. When I hear about needle stick injuries leading to Hepatitis B infection, it makes me concentrate on using universal or standard precautions.

37. Not recapping used needles and sharps to help prevent contracting HIV/AIDS is easy to do.

38. I am at risk for getting Hepatitis B.

39. Not recapping used needles and sharps helps to prevent contracting HIV/AIDS. $\begin{array}{lllll}1 & 2 & 3 & 4 & 5\end{array}$

$\begin{array}{lllll}1 & 2 & 3 & 4 & 5\end{array}$

$\begin{array}{lllll}1 & 2 & 3 & 4 & 5\end{array}$

$\begin{array}{lllll}1 & 2 & 3 & 4 & 5\end{array}$

$\begin{array}{lllll}1 & 2 & 3 & 4 & 5\end{array}$

$\begin{array}{lllll}1 & 2 & 3 & 4 & 5\end{array}$

$\begin{array}{lllll}1 & 2 & 3 & 4 & 5\end{array}$

$\begin{array}{lllll}1 & 2 & 3 & 4 & 5\end{array}$

$\begin{array}{lllll}1 & 2 & 3 & 4 & 5\end{array}$

$\begin{array}{lllll}1 & 2 & 3 & 4 & 5\end{array}$

$\begin{array}{lllll}1 & 2 & 3 & 4 & 5\end{array}$

$\begin{array}{lllll}1 & 2 & 3 & 4 & 5\end{array}$

$\begin{array}{lllll}1 & 2 & 3 & 4 & 5\end{array}$

\section{All Responses will be kept strictly anonymous.}




\begin{tabular}{|c|c|c|c|c|}
\hline $\begin{array}{l}1 \\
\text { Strongly } \\
\text { Disagree }\end{array}$ & $\begin{array}{l}2 \\
\text { Disagree }\end{array}$ & $\begin{array}{l}3 \\
\text { Neither } \\
\text { Agree or } \\
\text { Disagree }\end{array}$ & $\begin{array}{l}4 \\
\text { Agree }\end{array}$ & $\begin{array}{l}5 \\
\text { Strongly } \\
\text { Agree }\end{array}$ \\
\hline
\end{tabular}

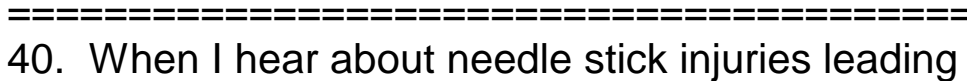
to HIV infection, I spend additional time thinking about them.

$\begin{array}{lllll}1 & 2 & 3 & 4 & 5\end{array}$

41. News of needle stick injuries leading to Hepatitis B infection makes me stop and think about my own personal safety.

$\begin{array}{lllll}1 & 2 & 3 & 4 & 5\end{array}$

42. I consistently recap needles when performing procedures that require their use.

$\begin{array}{lllll}1 & 2 & 3 & 4 & 5\end{array}$

All Responses will be kept strictly anonymous. 
PLEASE INDICATE YOUR FEELINGS REGARDING THE STATEMENT BELOW. CIRCLE THE NUMBER THAT BEST REPRESENTS YOUR RESPONSE.

43. Recapping needles to help avoid contracting HIV/AIDS is:

$\begin{array}{lllll}1 & 2 & 3 & 4 & 5 \\ \text { BAD } & & & & \text { GOOD }\end{array}$

44. Recapping needles to help avoid contracting HIV/AIDS is:

$\begin{array}{lrlll}1 & 2 & 3 & 4 & 5 \\ \text { UNDESIRABLE } & & & \text { DESIRABLE }\end{array}$

45. Recapping needles to help avoid contracting HIV/AIDS is:

$\begin{array}{lllll}1 & 2 & 3 & 4 & 5 \\ \text { A BIG DEAL } & & & & \text { NO BIG DEAL }\end{array}$

46. Recapping needles to help avoid contracting HIV/AIDS is:

$\begin{array}{lllll}1 & 2 & 3 & 4 & 5 \\ \text { HARMFUL } & & & & \text { NOT HARMFUL }\end{array}$

47. Recapping needles to help avoid contracting HEPATITIS B is:

$\begin{array}{lllll}1 & 2 & 3 & 4 & 5 \\ \text { BAD } & & & & \text { GOOD }\end{array}$

48. Recapping needles to help avoid contracting HEPATITIS B is:

$\begin{array}{lrlll}1 & 3 & 4 & 5 \\ \text { UNDESIRABLE } & & & \text { DESIRABLE }\end{array}$

49. Recapping needles to help avoid contracting HEPATITIS B is:

$\begin{array}{lllll}1 & 2 & 3 & 4 & 5 \\ \text { A BIG DEAL } & & & & \text { NO BIG DEAL }\end{array}$

50. Recapping needles to help avoid contracting HEPATITIS B is:

$\begin{array}{lllll}1 & 2 & 3 & 4 & 5 \\ \text { HARMFUL } & & & & \text { NOT HARMFUL }\end{array}$

All Responses will be kept strictly anonymous. 